\title{
An Automated BIM Model to Conceptually Design, Analyze, Simulate, and Assess Sustainable Building Projects
}

\author{
Farzad Jalaei and Ahmad Jrade \\ Department of Civil Engineering, University of Ottawa, 161 Louis Pasteur Pv., Ottawa, ON, Canada K1N 6N5 \\ Correspondence should be addressed to Farzad Jalaei; farzad.jalaei@uottawa.ca
}

Received 30 June 2014; Accepted 13 October 2014; Published 6 November 2014

Academic Editor: F. Pacheco-Torgal

Copyright ( 2014 F. Jalaei and A. Jrade. This is an open access article distributed under the Creative Commons Attribution License, which permits unrestricted use, distribution, and reproduction in any medium, provided the original work is properly cited.

\begin{abstract}
Quantifying the environmental impacts and simulating the energy consumption of building's components at the conceptual design stage are very helpful for designers needing to make decisions related to the selection of the best design alternative that would lead to a more energy efficient building. Building Information Modeling (BIM) offers designers the ability to assess different design alternatives at the conceptual stage of the project so that energy and life cycle assessment (LCA) strategies and systems are attained. This paper proposes an automated model that links BIM, LCA, energy analysis, and lighting simulation tools with green building certification systems. The implementation is within developing plug-ins on BIM tool capable of measuring the environmental impacts (EI) and embodied energy of building components. Using this method, designers will be provided with a new way to visualize and to identify the potential gain or loss of energy for the building as a whole and for each of its associated components. Furthermore, designers will be able to detect and evaluate the sustainability of the proposed buildings based on Leadership in Energy and Environmental Design (LEED) rating system. An actual building project will be used to illustrate the workability of the proposed methodology.
\end{abstract}

\section{Introduction}

Important decisions related to the design of sustainable buildings are made at the conceptual stage of their lives. This practice does not consider the integration between the design and energy analysis processes during early stages and leads to an inefficient way of backtracking to modify the design in order to achieve a set of performance criteria [1]. Energy efficiency is an important feature in naming building materials as being environmentally friendly. The ultimate goal in using energy efficient materials is to reduce the amount of artificially generated power that must be brought to a building site [2]. Generally, building materials consume energy throughout their life cycle starting by the manufacturing stage, passing through that of use, and finishing by the deconstruction phase. These stages include raw material extraction, transport, manufacture, assembly, installation as well as disassembly, deconstruction, and decomposition. The total life cycle energy of a building includes both embodied energy and operating energy [3]. Embodied energy is sequestered in building materials during all processes of production, on-site construction, transportation, final demolition, and disposal. Operating energy is expended in maintaining the inside environment through processes such as heating and cooling, lighting, and operating appliances.

Presently, Building Information Modeling tools have the ability to provide users with an opportunity to explore different energy saving alternatives at the early design stage by avoiding the time-consuming process of reentering all the building geometry and supporting information necessary for a complete energy analysis. Using BIM helps owners and designers make energy related decisions that have a high impact on the proposed building life cycle cost at the early stage of design. Krygiel and Nies [4] indicate that BIM can aid in the aspects of sustainable design which include building orientation, building massing (that is used to analyze building form and optimize the building envelope), daylighting analysis, water harvesting (that is used to reduce water needs in a building), energy modeling (that helps reducing energy needs and analyzing how renewable energy options can contribute to low energy costs), sustainable materials (that helps reducing material needs by using recycled materials), 
and site and logistics management (to reduce waste and carbon footprints).

Hoff [5] describes EI as being the result of the inputs and outputs over a product's life cycle. Although the total number of different potential EIs may be very large, the U.S. Environmental Protection Agency has categorized the "top ten" impacts as (1) Global Warming Potential, (2) Ozone Depletion Potential, (3) Photochemical Oxidant Potential, (4) Acidification Potential, (5) Eutrophication, (6) Health Toxicity (Cancer), (7) Health Toxicity (Non-Cancer), (8) Health Toxicity (Air Pollutants), (9) Eco-Toxicity Potential, and (10) Fossil Fuel Use. Thus, to quantify the impacts of the selected materials on the environment, an assessment method has to be applied. The common method employed is LCA, which is a tool used for evaluating environmental concerns [6]. It is because of this that designers must keep the entire life cycle of the building and its associated materials in mind. This will promote sustainable development practices through suited rating systems by recognizing the projects that implement strategies for better environmental and health performance [7]. Furthermore, linking BIM with LCA tool supplies users with information related to the embodied energy needed for every single component present in the proposed building and, accordingly, allows them to select the best components at the conceptual design stage.

Usually, using BIM tools to design sustainable buildings necessitates the selection of materials and systems whose embodied energy can be easily evaluated. Thus, the common method used to quantify the embodied energy of the selected materials is LCA. For this purpose, designers use LCA tools to model, to modify, and to input energy simulation results and calculate the embodied effects of their design. Hence, it will be necessary to evaluate and to compare the capabilities of these file formats in exchanging information between BIM and LCA tools, which are highly important for designers who need to transfer the design information directly from the BIM model to the energy analysis software. Yet, using BIM tools to design sustainable buildings necessitates the selection of materials and systems so that their EI and embodied energy can be easily evaluated. Thus, the common method used to quantify the EI and embodied energy of the selected materials is LCA. For this purpose, designers can use "The Impact Estimator for Buildings," which is a stand-alone tool that allows users to model their own custom assembly and envelope configurations and provides them with the flexibility to modify the proposed designs and existing buildings. Hence, the main objective of this paper is to automate the integration process of BIM, LCA, and energy analysis and simulation tools to design sustainable buildings. This assimilation will also include the sustainable design for proposed buildings at the conceptual stage in an attempt to help owners and designers analyse the daylighting and measure the thermal of such types of buildings. To make this integration fully automated, authors developed plugs-in in BIM tool to enable users transfer their design information directly from the BIM model to the energy analysis software. In this way, users can easily export the materials' quantity take-offs and connect them to other tools such as the LCA tool so that designers can have relevant information about the EI and embodied energy for associated components of the designed building at the conceptual stage. Access to said information will then allow them to determine and correct potential problems.

Furthermore, designers are able to evaluate the sustainability of the building components used in the BIM model by using another plug-in in BIM tool which supports suppliers' web pages by cataloguing green components and products and their environmental characteristics. In addition, by assigning the unit cost of every building component in BIM tool, design team is able to create supportive documents such as initial cost estimation of the BIM model. Using the proposed automated process at the conceptual stage of the project enables designer to determine which products best meet their needs, evaluate them based on optional environmental rating systems, and print the necessary documents in an easy, quick, and convenient way.

\section{Literature Review}

Building Information Modeling (BIM) is gaining popularity in the building industry where it was first coined over ten years ago to distinguish the $3 \mathrm{D}$ modeling rich information from traditional 2D drawings. Currently, BIM is widely adopted by the building industry due to its ability to correct mistakes at the early stages and aid in accurately scheduling and sequencing the construction, identifying conflicts, advocating design alternatives, and facilitating the selection of appropriate solutions for complex projects [8,9]. Based on Kubba [8] and Becerik-Gerber and Rice [10], development of a schematic model prior to the generation of a detailed building model allows the designer to make a more accurate assessment of the proposed scheme and evaluate whether it meets the functional and sustainable requirements set out by the owner; this helps increase project performance and overall quality. The advent of BIM along with the emergence of global challenging issues like sustainability and life cycle cost of buildings necessitates designers to incorporate the basic performance analysis from an early design phase. That is special quality analysis, energy performance, social impact, and environmental performance into its framework by further developing the concept of virtual space and virtual building [11]. An integrated BIM system can facilitate collaboration and communication processes between project participants in an early design phase to effectively provide a well performing building during operations [12].

Combining sustainable design strategies with BIM technology has the potential to change the traditional design practices and to efficiently produce a high-performance design of proposed buildings. BIM technology can be used to support the design and analysis of building's systems at the early design process. These include the experimental structural analysis, the environmental controls, the construction method, the selection of new materials and systems, and the detailed analysis of design processes. The building system analysis involves many functional aspects of the building system such as structural integrity, ventilation, temperature control, circulation, lighting, energy distribution, 
and consumption [13]. Hence, an ideal opportunity exists for the sustainability measures and performance analysis to be integrated within the BIM model [14]. BIM includes associated benefits of visualization, built-in intelligent objects of a building model such as spatial data (3D), unstructured data (text), and structured data such as spreadsheets and databases. BIM models not only provide data pertained to the building geometry but also allow the calculation of volumes and related energy based on the building's characteristics and orientation.

Energy analysis is typically performed after the architectural/engineering design and related documents have been produced. This practice does not consider the integration between the design and energy analysis processes during early stages and leads to an inefficient way of backtracking to modify the design in order to achieve a set of performance criteria [1]. For the past 50 years, a variety of building energy simulations and analysis tools have been developed, enhanced, and applied throughout the building industry. Examples of these tools are BLAST, EnergyPlus, eQUEST, TRACE, DOE2, Ecotect, and Integrated Environmental Solution (IES-VE) [15]. Grobler [16] claimed that building designs (conceptual and detailed) affect the construction and operation costs of a building. Several researchers describe energy analysis as a holistic evaluation [17]. Dahl et al. [18] and Lam et al. [19] show that decisions made early in a project have a strong effect on the life cycle costs of a building. Simulation tools, such as Integrated Environmental Solution-Virtual Environment (IES-VE) and Ecotect, are able to conduct comprehensive building performance analysis, including energy simulation. IES has direct interaction with BIM tools such as Autodesk Revit. Ecotect is a building design and environmental analysis tool that covers a broad range of simulation and analysis functions required to understand how a building design will operate and perform. It allows designers to work easily in 3D and to apply tools necessary for an energy efficient and sustainable future. Some of its features include a shading design and solar analysis, lighting analysis, acoustic analysis, thermal analysis, ventilation and air flow analysis, building regulations, and resource management. Ecotect does not have a plug-in in BIM tools; therefore the way it can get connected with BIM tools is through file format exchanges.

Jalaei and Jrade [20] evaluated and compared the capabilities of different file formats in transferring information from BIM tool into energy analysis and simulation applications. The result of this validation showed that gbXML has a simplified schema for energy analysis, although that when preparing an analytical model from BIM 3D model to be imported via gbXML file format is time-consuming for large and complex projects, it is currently a preferred format during design development or the schematic stage. The green Building XML schema-commonly known as "gbXML"was developed to facilitate the transferring process for the information stored in building information models to enable the integration and interoperability between the design models and other engineering analysis tool [21]. However, gbXML also facilitates the exchange of the building information (which includes product characteristics and equipment performance data) between the manufacturer's database, the BIM models, and the energy simulation engines. One of gbXML's benefits is its ability to carry detailed descriptions of a single building or a set of buildings which can be imported and used by energy analysis and simulation tools.

When creating sustainable designs, designers are concerned about their ability to evaluate the EI of the selected materials and components by using available methods and tools. In this perspective, the idea of LCA has emerged as the collection and evaluation of the building inputs and outputs and the potential energy of a product throughout its life cycle [22]. While LCA can be used to assess the sustainability of the built environment, its technique provides comprehensive coverage of the product's energy consumption, as such it is very useful to apply it to the conceptual design phase of building projects. At that stage the designer must be able to acquire, store, and organize LCA data for the components in such a way that it can be used to generate feedback during the design process [23].

In order to analyze the EI as well as embodied energy of buildings' components, a methodology that integrates BIM models with LCA systems is needed due to its potential to streamline LCA processes and facilitate the rigorous management of the environmental footprint of constructed facilities. Jrade and Jalaei [24] describe a methodology emphasizing the integration of BIM, Management Information System, and LCA that can be used to implement sustainable design for proposed buildings at their conceptual stage all the while taking into consideration their environmental impacts. Häkkinen and Kiviniemi [25] identify the following solutions to integrate BIM tools with LCA systems: (1) linking separate software tools via file exchange, (2) adding functionality to existing BIM software, and (3) using parametric formats such as Geometric Description Language (GDL). Until recently, only operating energy was considered, owing to its larger share in the total energy life cycle. However, due to the advent of energy efficient equipment and appliances, as well as more advanced and effective insulation materials, the potential for curbing operating energy has increased and, as a result, the current emphasis has shifted to include embodied energy in the building materials $[3,26]$. Thus, there is a genuine demand for measures to calibrate the performance of buildings in terms of both embodied and operating energy in order to reduce their energy consumption [27, 28]. Transport energy is a function of material's weight, transport method, and the travelled distance. From these three factors a reasonably accurate calculation of the transport embodied energy can be done.

While green building certification systems can be used as guidance for design, to record performance progress, to compare buildings, and to document the outcomes and/or strategies used in the building [29], different types of methodology such as Building Research Establishment Environmental Assessment Method (BREEAM) [30], Green Star from Australia [31], and the Comprehensive Assessment System for Building Environmental Efficiency (CASBEE) from Japan [32] have been developed. More locally, we can also find the Building and Environmental Performance Assessment Criteria (BEPAC) from Canada [33] and the Leadership in 
Energy and Environmental Design (LEED) from the United States [7]. All of these methodologies are widely used to establish the environmental goals' level of achievement and to guide the planning and design processes. Furthermore, comprehensive tools for environmental assessment can be found such as the whole Building Design Guide [34] and the World Green Building Council [35].

Although these tools have an extended use, the LEED Rating System (LEED-RS) has established a strong credibility among the experts [36]. The LEED-RS was evaluated to its importance as a measurement tool for the environmental performance of a building by 7,500 companies and organization members around the world. Yet, in order to automate the evaluation of the environmental specifications of the proposed building model in BIM at the conceptual design stage, designers can use sustainability evaluator tool (i.e., EcoScorecard( $)$, which is a plug-in to BIM tool. This Plug-in has the ability to evaluate and to document the environmental data for various rating systems such as those of the US Green Building Council (USGBC), the Canadian Green Building Council (CaGBC), the Collaborative for High Performance Schools (CHPS), and the National Green Building Standard (NGBS) as well as other third-party product certification systems. LEED Canada-NC 1.0 (NC standard for new construction and major renovations) is the Canadian version of the LEED certification system. It is approved by the USGBC and was released by the CaGBC in December 2004. An addendum to LEED Canada-NC 1.0 was developed in 2007, which included improved requirements introduced by the USGBC for LEED-NC 2.2, along with other improvements related to the durable building credit. The CaGBC is the source for these LEED reference information and updates, including templates.

Despite that lots of efforts have been put in place toward the advancement of sustainability, still the energy efficiency and its resulting values besides the corresponding cost savings are not key criteria in the building development process. Energy and performance analysis are typically performed after the architectural design and construction documents have been produced. This lack of integration into the design process leads to an inefficient process of retroactively modifying the design to achieve a set of performance criteria. The importance of incorporating all disciplines from the early stages of design is widely acknowledged and documented [37]. Early decisions are crucial in order to achieve sustainability objectives in the resulting design outcome [1]. According to Eastman et al. [38], developing a parametric model within the BIM environment is capable of capturing project information and generating documentation. With special care taken on the software side, an enhanced BIM application could potentially resolve what used to be major problems in the delivery of sustainable design (i.e., dealing with the complexity of conducting a full building energy simulation, acoustical analysis, and daylighting design). The authors are not able to find in the literature any research that looked at the possibility of having the design team to have access to different types of information such as energy consumption, environmental impacts, and embodied energy of every building component, pursued accumulated green building rating system points, and associated costs all within a BIM environment, while the conceptual design is in progress. Although the potential of using BIM models for energy simulation is well known, a systematic approach that can be used to share the necessary information is still lacking [39]. The data related to the buildings internal loads such as occupancy and lighting should be included in the data exchanging process between BIM tools and energy simulation software in order to avoid any repetitive data inputs [40]. To pursue the integration procedure is to test the data inputs and outputs using different interoperable formats and to select the more efficient one. Since the automation process will take place at the conceptual stage of a project life while doing sustainable design, another aspect of this study is to use an application to evaluate the created model in order to get details about its environmental and sustainability specifications in a systematic way. In this case, users can add up the potential points that can be earned during the design based on the selected green building certification system. This would provide the design team with the opportunity to analyze energy results for the whole model as well as EI and the embodied energy of every component. Autodesk Revit, which is used as BIM tool in this research, provides the opportunity to create custom tools that plug directly into Autodesk Revit. This would extend the functionality of the BIM tool and would allow users make well-informed decisions in selecting optimum sustainable building components.

\section{Scope and Significance of the Study}

This paper describes a methodology to implement an automated and integrated platform to do sustainable design for proposed buildings at their conceptual stage. The methodology is implemented through the design and development of a model that simplifies the process of designing sustainable buildings and hence of transferring the design information to energy analysis tools so that designers can implement energy and lighting analysis. The model has also the capability of listing the certification points that can potentially be earned based on the selected system for sustainability. The methodology incorporates an integrated model capable of guiding users when performing sustainable design for building projects. It incorporates five modules: (1) database management system (DBMS), (2) BIM, (3) energy and lighting analysis, (4) life cycle assessment (LCA), and (5) LEED and cost. The major task of the model is to expand, develop, and collect lists of green products and certified materials; these materials will be linked to the BIM tool. Part of this integrated methodology is to develop plug-ins and customize the available ones in BIM tool so that users can connect their design module with other modules in an efficient and consistent manner. The objectives of this study are listed as follows.

(i) Collect and store series of design families that incorporate sustainably certified components in a database in an attempt to improve the workability and capability of the BIM tool used to do sustainable design at the conceptual stage. 


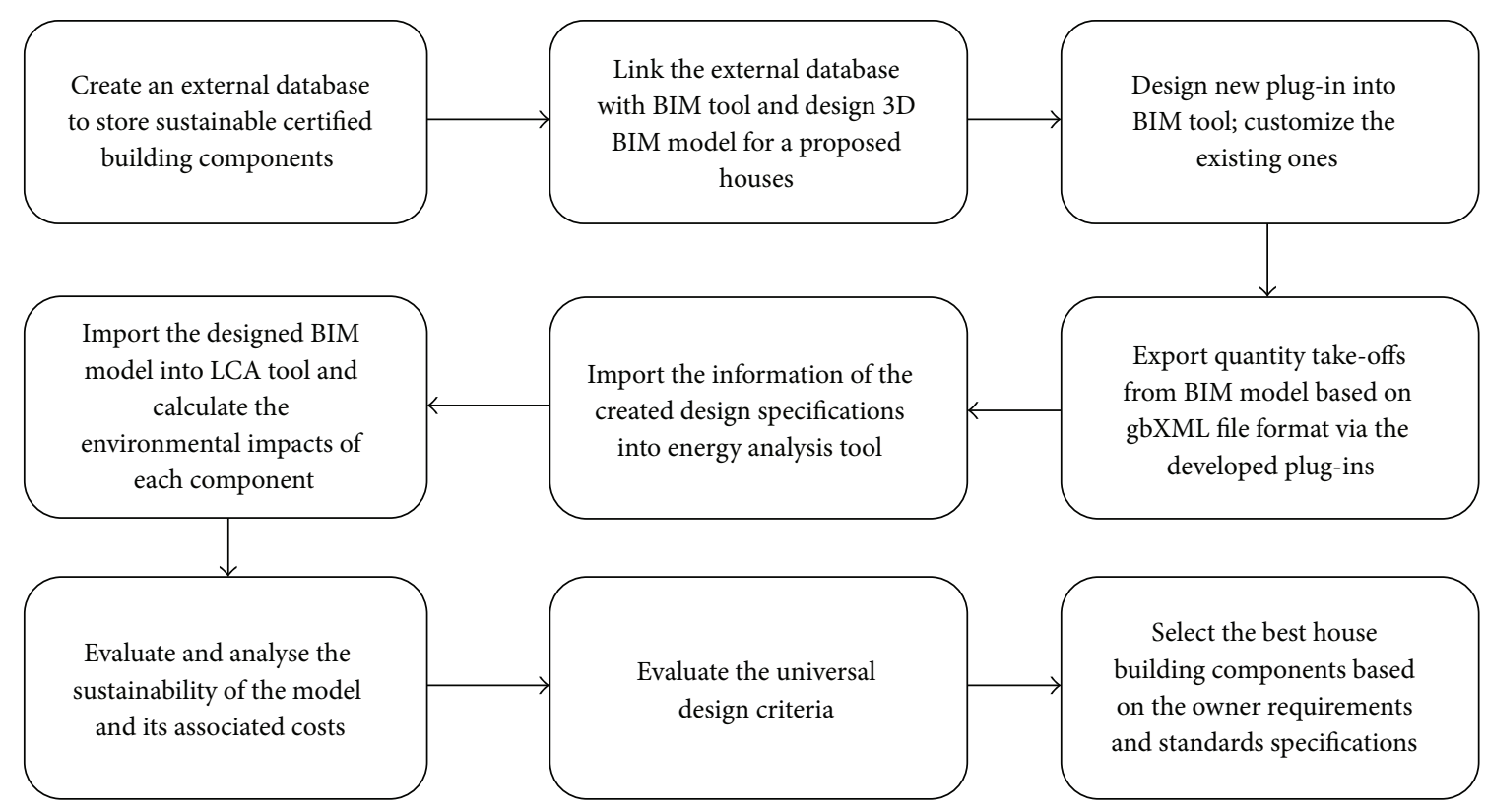

Figure 1: Methodology of the integration system.

(ii) Create and develop a framework for this integration that considers the sustainable design requirements and the functionality of BIM tool.

(iii) Investigate the feasibility of implementing a full integration between BIM and energy (operational and embodied) and lighting analysis tools.

(iv) Develop the automated BIM model that integrates the abovementioned five modules and then validate it by using an actual existing building project to test its workability and capability. Afterwards, analyze the information associated with the case project to identify how much was transmitted during the transformation process between the different tools.

One contribution of this research is the ability to measure the transport energy, which is one significant component of the embodied energy used to transfer materials and building components from suppliers' location to the building site. IE tool does not recognize this type of energy and accordingly it does not have the capability to calculate it.

Different types of software commonly used in the construction industry, such as Autodesk Revit Architecture $\odot$, Autodesk Ecotect, Integrated Environmental Solutions (IESVE), Microsoft Excel $\odot$, and Athena Impact Estimator $\odot$ were used in the development of the proposed model.

\section{Methodology and Model Development}

The aim is to develop an automated way in which 3D sustainable design of a proposed building project is accomplished and related energy analysis and simulation results of the whole building and every one of its components identified.
Since the proposed methodology integrates different applications, as is represented in Figure 1, the development will be implemented through the following six phases.

Phase 1.It consists of designing the model's relational database needed to design sustainable building. Loucopoulos and Zicari [41] stated that a consistent information system depends on the integration between databases, programming languages, and software engineering and its lifecycle incorporates the interrelated technologies of conceptual modeling and database design. The design and development of this database is accomplished in two steps starting by the conceptual modeling and ending by the physical implementation. The information related to the green materials is stored in an external database in the form of predefined design families that can be recognized by BIM tool. The separate database is linked to the predefined library of Revit by defining its path and it is loaded every time the BIM tool (Revit) opens. The data related to the green materials is saved as family files (RFA) or Revit files (RVT), which can be identified by the BIM tool. Thus, in the external sustainable database, up to 3,000 design families are collected from the literature, suppliers' web pages, USGBC, and CaGBC websites as well as published data and are arranged based on the 16 divisions of the Masterformat WBS. Different types of information such as details about the materials used, suppliers' contact data, assigned keynotes, potential LEED criteria, and assembly codes are stored in the external database.

Phase 2. Phase 2 focuses on customizing BIM tool to fit the modularity requirements of the model. The first step is to design and implement a 3D module capable of storing newly created families, in BIM tool, and their associated keynotes for components commonly used in residential buildings by using certified green materials. The module is linked to 
TABLE 1: Sample of the algorithm developed to transfer the material quantity take-offs from BIM model to energy analysis tool.

\begin{tabular}{|c|c|}
\hline Integration algorithm used to create plug-in & Task \\
\hline 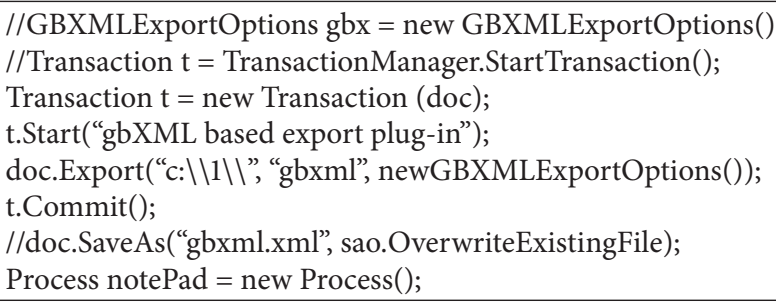 & $\begin{array}{l}\text { Export and save material quantity take-offs to gbXML } \\
\text { format }\end{array}$ \\
\hline $\begin{array}{l}\text { notePad.StartInfo.FileName = "Ecotect.exe"; } \\
\text { notePad.StartInfo.Arguments = "C: } \backslash \backslash 1 \backslash \backslash \text { gbxml.xml"; } \\
\text { notePad.Start(); }\end{array}$ & $\begin{array}{l}\text { Call Ecotect.exe to open gbXML files from the place } \\
\text { where it is already saved }\end{array}$ \\
\hline
\end{tabular}

the database developed in phase 1 . Keynotes are textual annotations that relate text strings to specific elements in the model, which are in turn linked to an external text file. It can be used as external link to the element itself with specific style and specifications so it can be used as a Revit family. That means, user can insert different text family types in Revit. Keynotes can be assigned to elements which are typically used if the user wants to note an entire assembly, such as a wall assembly. The sixteen Masterformat divisions present the main WBS applied in this research. It is very important to select a unique code for each item that is presented in a separate line in the database to ease and simplify their usage.

Phase 3. It focuses on creating a plug-in, which is a type of algorithm that adds functionality to the BIM tool by integrating it with the energy analysis and simulation tools. Plug-In or Add-In are terms used in BIM tool to signify a module containing an algorithm that makes use of the BIM tool's Application Program Interface (API). The BIM tool used in this study has a.NET API, which means that any of the.NET compliant programming languages (C\#, VB.NET, $\mathrm{F} \#$, etc.) can be used to develop a customized plug-in. While each language has its own relative benefits, $\mathrm{C \#}$ has been used in this research due to its simplicity, usability, and powerful ability to underlay the.NET framework. Table 1 represents sample of the developed algorithm used to export the materials quantity take-offs to energy analysis tool based on gbXML format. This algorithm uses C\# programming language, which is used in developing the plug-ins that will be applied to the BIM tool.

Phase 4. It consists of designing energy analysis and simulation modules that help exporting the $3 \mathrm{D}$ design created in BIM tool as gbXML file format. The energy analysis tools used in this research is Ecotect, due to its efficiency in evaluating the thermal and solar gains for the architectural designs of proposed buildings. It easily creates or cleans up models in a format that includes both the geometry and the zones of a building, besides having interoperability potentials with other tools. This interoperability makes it an ideal tool to import and export the 3D design between BIM tools, which generate the geometry of the proposed building, and different energy analysis tools. IES-VE contains an Integrated Data Model that captures all the information related to the proposed building including the geometric data, which is needed to do all necessary analyses. Yet, it must be said that the $3 \mathrm{D}$ geometric information can also be imported straight from the BIM tool using gbXML file format. Constructions materials can also be selected from the IES-VE built-in database, which is known as the Apache construction database.

Phase 5. It concentrates on designing LCA modules that interconnect the 3D BIM design with the LCA tool through an ODBC exporting format, which directly transfers the materials' quantity take-offs to any file format in an attempt to evaluate their environmental impacts. The LCA tool is linked to an external database, which is in turn associated with the BIM module that stores the extracted quantities of materials from the 3D design and evaluates their EI as well as embodied energy. The extracted bill of quantity is then linked to ATHENA Impact Estimator` in a text exchange file format. Authors elected to use ATHENA Impact Estimator for Buildings because it is commonly used by the North American construction industry and because it is designed to evaluate the whole building and its assemblies based on the internationally recognized life cycle assessment (LCA) methodology.

Lots of materials are delivered to the site by rigid trucks; thus to calculate the transportation energy, the developed model considers this as one of the inputs stored in the database developed in phase 1 . To ease the development process of this module a framework is created.

Transportation embodied energy is dependent on the type and number of trucks, the travel distance between suppliers and construction site, and material properties (i.e., size and weight). In order to demonstrate the model's capabilities, four different types of trucks (as listed in Table 2) are taken into account when identifying the required number of trucks. In this study, a gross vehicle weight (GVW) is considered as the maximum weight value of a vehicle that includes weight of a vehicle and cargo and a payload is defined as the total weight of all cargo that a vehicle carries. Also, the size of the load in the truck bucket is limited to $53 \times 13.5 \times 8.5 \mathrm{ft}$ $(L \times H \times W)[42]$. Using the properties identified above and quantity of material for a given order, the required number of trucks can be determined. The proposed algorithm selects combination of trucks based on the minimum value of fuel 
TABLE 2: Descriptive attributes for each type of trucks selected for the case building.

\begin{tabular}{|c|c|c|c|c|}
\hline Truck type & GVW (lb) & Payload (lb) & $\begin{array}{l}\text { Fuel consumption } \\
\text { (MPG) }\end{array}$ & MPG for empty truck \\
\hline 1 & 36,300 & 25,300 & $-0.0246 W+6.63$ & 6.62 \\
\hline 2 & 60,600 & 40,800 & $-0.0258 W+6.285$ & 6.26 \\
\hline 3 & 80,000 & 55,750 & $-0.0255 W+6.205$ & 6.18 \\
\hline 4 & 92,000 & 66,200 & $-0.0263 W+5.885$ & 5.86 \\
\hline
\end{tabular}

$W$ : total weight of load $(1000 \times \mathrm{lb})$.

consumption. Then, the fuel consumption value is calculated according to the traveled distance per unit of fuel used in miles per gallon (MPG). The distance measurement can be done by using the geospatial method used by BIM tool that specifies the geographic location for the project. It uses an Internet mapping service to visualize the project location by searching its street address or the longitude and latitude of the project.

Phase 6. It includes the design and development of a green building certification and cost estimating module, which is linked to the BIM. This module contains data collected from the suppliers and publishers webpages, which are retrieved from the created model by using the sustainability evaluator plug-in that is loaded into BIM tool. Authors collected information about sustainable materials and components from the manufacturers and vendors websites as well as using the smart BIM green components, which can be detected by the sustainability evaluator. In the sustainability evaluation results, there is detailed information about every component, which includes the potential LEED points that can be gained if these materials or components are used in the design. This information is stored in the external database of the BIM tool. Therefore, when designers model the design for a proposed building project in $3 \mathrm{D}$ and select any of these sustainable materials or components, the potential LEED points gained by these selected items are identified and stored in the schedule associated with the model. Afterwards, users will add up these LEED points to identify the potential number that the proposed building can earn and accordingly its potential level of certification (Certified; Silver; Gold; or Platinum). Furthermore, the associated cost will be generated by linking the model created in BIM tool with the cost module, which is linked to the database that stores information about green and certified materials. The associated cost of the developed design is then calculated based on RS-Means published data.

\section{Model Application}

The development of the model described in this paper focus on automating the process of connecting the output of BIM module with other different modules. The developed model is an integrated tool that helps owners and designers share variety of information at the conceptual design stage of sustainable buildings. It assists designers in comparing and evaluating each design family and its associated components that is selected during the conceptual design taking into consideration the materials' selection criteria.
Figure 2 shows a flowchart of the integration process that is used in this study. It determines the processes applied to the design created in BIM tool while considering all related criteria and specifications based on the described phases. Figure 3 illustrates the model's architecture when the input section includes the certified components stored in the database, based on the Masterformat WBS, containing keynotes and families as well as suppliers' information. Project orientation and the specified green building rating system for sustainability analysis are identified as inputs. The criteria section includes the green building rating system as well as the environmental performance and principles to select green materials. The main output of the model will be a sustainable design in 3D mode of the proposed building that includes lists of the selected sustainable materials and their environmental impacts as well as the results of the energy simulation and daylight data analysis. This platform provides a suitable environment to establish a Decision Support System (DSS) to help design team decides on the selection of the most appropriate type of sustainable building components and families for proposed projects based on defined criteria (i.e., energy consumption, environmental impacts, and economic properties) in an attempt to identify the influence of the design variations on the sustainable performance of the whole building. The final design will be influenced by the results of the energy and lighting analysis, the LCA and environmental impact and embodied energy results, and the sustainability evaluation of every building component based on LEED rating system besides the initial costs of these components. These results represent a reasonable perspective to evaluate how far the design deviates from the standards and owners' expectation.

To validate this model, its performance is examined through the use of an actual three floor office building project with a conference hall at the fourth floor that is under design process in the city of Montreal. The proposed construction site has a total area of $41,980 \mathrm{ft}^{2}$, the building's gross area is $16,862 \mathrm{ft}^{2}$, and it has a perimeter of $1145 \mathrm{ft}$. The authors created a 3D conceptual design of the current project where its associated sustainable components and materials were selected from the developed database. The components used in the design of the case example had their specifications as close as possible to the ones used in the real design. Every component, such as the floor, walls, the roof, and windows has its associated LEED information linked to the families of the BIM tool and they are already defined in the database of EcoScorecard, which includes the manufacturers' 


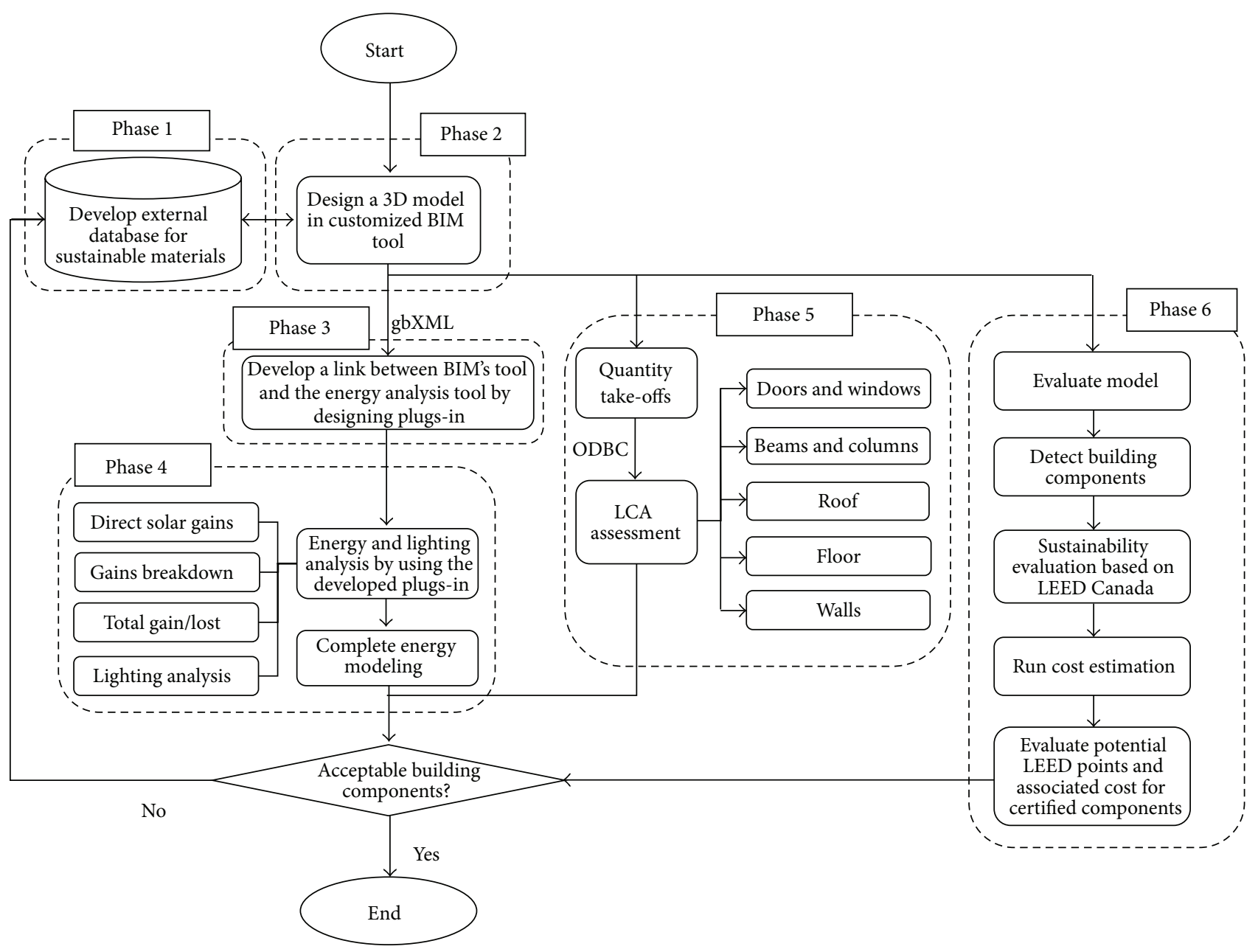

FIGURE 2: Flowchart of the integration process.

web pages and contact information. The authors created a conceptual design of the current project where its associated sustainable components and materials were selected from the developed database. The components used in creating the design of the case building had their specifications very close to the ones used in the real design. Every component, such as floor, walls, roof, and windows, has its associated LEED information linked to the families inherited in BIM tool and is already defined in the database of the sustainability evaluator tool (EcoScorecard), which includes the manufacturers' web pages and contact information. The developed model will be used to analyze and simulate the energy and lighting of the project's $3 \mathrm{D}$ design and to evaluate its sustainability by calculating the accumulated LEED points that can potentially be earned during the conceptual design stage. Figure 4 shows a rendered snapshot of the proposed sustainable office building, which was created using the developed model previously described. This process is implemented in four steps, wherein the model's capabilities and performance are measured using the inherited modules.

5.1. Sustainable Conceptual Design in BIM Tool (Step 1). BIM tool (Autodesk Revit Architecture (C) is applied to do the sustainable 3D conceptual design of the case building by using green families and their related keynotes stored in the external database. Once these families' keynote file is linked to the building model, users will select the most appropriate type of certified materials and components for their design. As explained in phase 1, the external database contains detailed information about the suppliers of the green materials used in every family. More than $80 \%$ of the components and families used in the case building had their LEED certification points supplied by their manufacturers and stored in the developed external database.

5.2. Energy Analysis and Daylighting Simulation (Step 2). In order to have an accurate energy analysis of the case building, its created 3D geometric model should be converted into an analytical model. First, we have to convert all the spaces into rooms. In BIM tool, rooms are considered to be the equivalent of zones that need to be defined. A thermal zone is a completely enclosed space bounded by its floors, walls, and roof and is the basic unit for which the heat loads are calculated. The extent of a "room" is defined by its bounding elements such as walls, floors, and roofs. Once a "room" is defined for the purpose of analysing the building's 


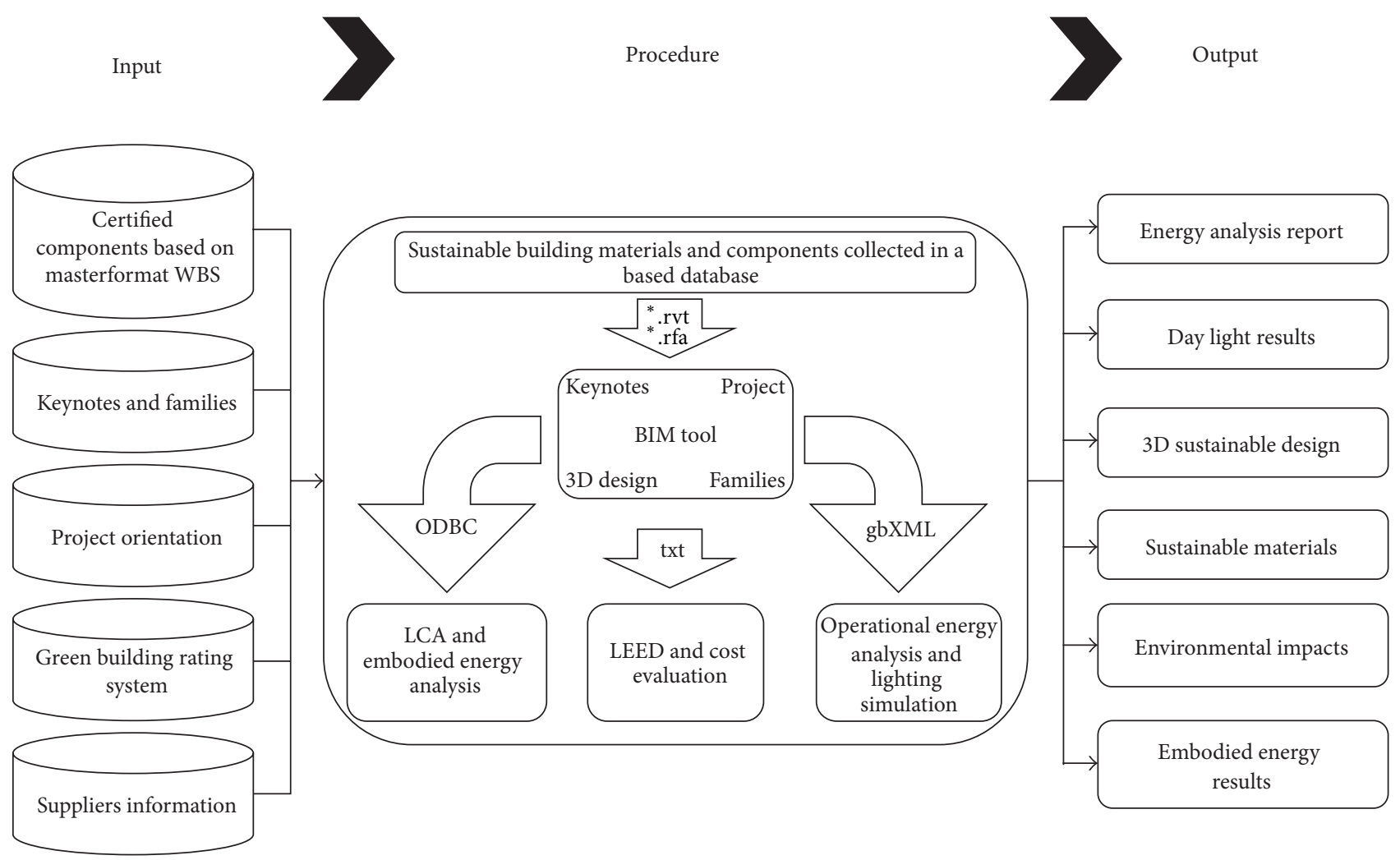

FIgURe 3: Model's architecture.

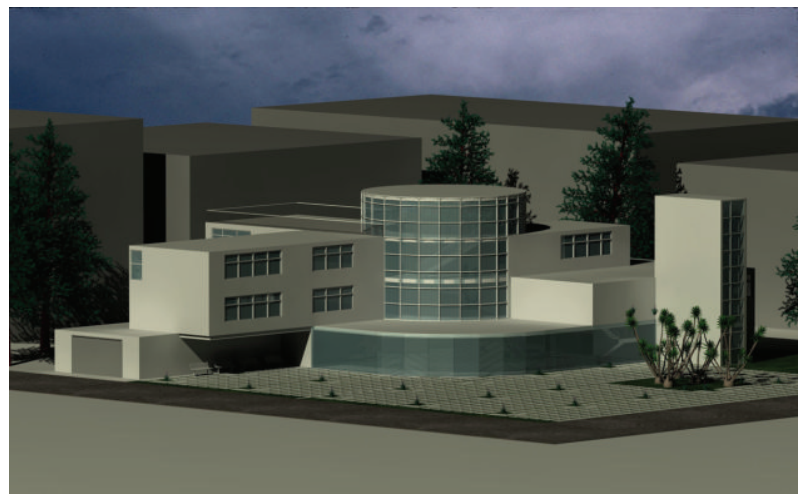

FIGURE 4: Snapshot of the sustainable case building model.

energy, these bounding elements are converted to 2D surfaces representing their actual geometry. However, overhangs and balconies, which do not have a room, are considered as shading surfaces. In order to determine whether a room is an interior or an exterior, it is important to define that it is adjacent in the analytical model. By using the developed plug-in that is loaded in the BIM tool, designers will directly transfer the created 3D model of the building to the energy simulation and analysis tool (Ecotect( ) using gbXML format. Moreover, by using the IES-VE plug-ins, which is added to the BIM tool, transferring the 3D BIM model into IES-VE is conceivable based on gbXML format as shown in Figure 5.
After running the thermal and daylighting analysis in Ecotect, it is possible that comprehensive building information other than the geometric one will be transported. In order to test what type of data was included during the integration, a comparison analysis of this data is executed. The building model is tested for building material, thickness, geometry (area and volume), building services, location, and building types. All the input variables are kept constant in the base case while the testing is done with one alteration at a time. What BIM brought to energy simulation is an integrative interface that provided the designers a more reliable and consistent building information model for analysis, leading to more accurate simulation results. The biggest advantage of parametric modeling rests in its capacity of updating building information simultaneously with the changes made to the model configuration. In the conceptual design stage, architects and designers could test different design alternatives to find the optimal solution.

As mentioned earlier, gbXML is developed based on $\mathrm{XML}$, which captures data information representation but not the relationships among them. All the geometry information imported from the BIM tool is represented by the "Campus" element. The global child element "Surface" represents all the surfaces in the geometry. There are several attributes defined in a "Surface" such as "id" and "surfaceType." Every "Surface" element has two representations of geometry, "PlanarGeometry," and "RectangularGeometry." They both carry the same geometry information. The purpose of this is to double-check whether the translation of geometry from BIM 


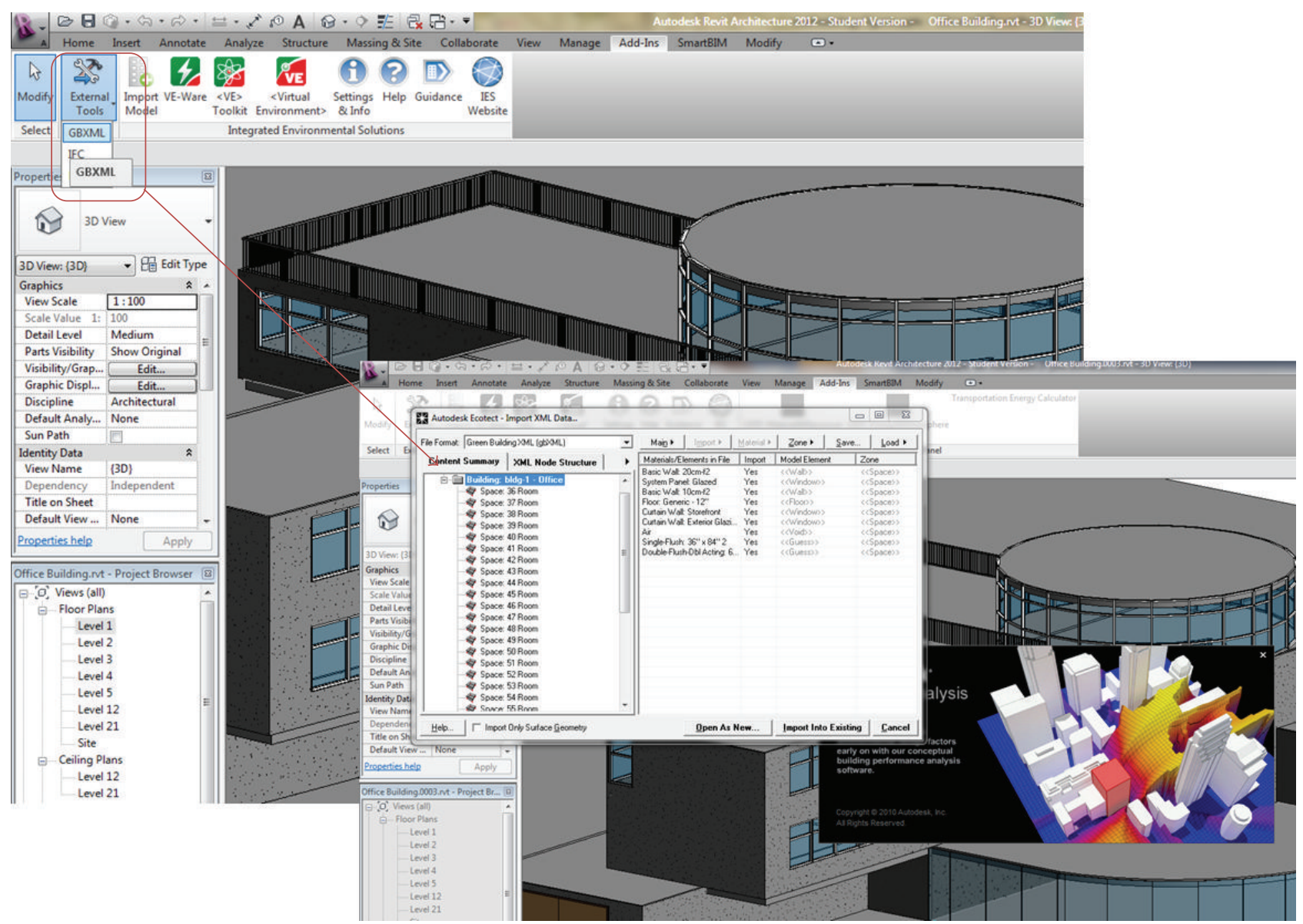

FIGURE 5: Snapshot of directly transferring BIM model to Ecotect via plug-in based on gbXML file format.

tool is correct or not. Every "RectangularGeometry" has four "CartesianPoint" elements, which represent a surface. Every "CartesianPoint" is represented by a three-dimensional coordinate $(x, y, z)$.

There are only five levels to transverse and to get all the coordinates of an "Exterior Wall" location. It is also easy to add other surfaces. In addition, every polyloop, which contains a list of coordinates that makes up a polygon in three-dimensional space, follows a right-hand rule defining the outward normal of a surface. However, gbXML has the ability to carry building environmental sensing information. In terms of geometry, gbXML only accepts rectangular shape, which is enough for energy simulation.

GbXML file is able to transfer the geometric information such as shape, areas, and volumes. However, it is further able to transmit information about location and construction assignments. It can be seen that the gbXML file is also able to transfer other information such as building type (single family) and building services (VAV single duct). Thus, in order to validate the information that is not transmitted, the gbXML file is modified so that it can recognize the information related to the location, building services, and construction assignments while executing the transferring process.
In order to discern that the information related to the selected material used in the model has been completely transmitted over to the energy simulation and analysis tools, a new material is assigned to the $3 \mathrm{D}$ model of the case building. The wall's material is changed to a timber frame wall that consists of brickwork (outer leaf), cavity, plywood (lightweight), mineral fiber slab, and cavity and gypsum plasterboard. However, the option selected in the IES interface for the construction assignments (exterior wall) is kept unchanged.

A quick scan to the IES's results shows that the result is kept unaltered. This means that the newly assigned material in the model does not have any type of effect on the results. To clarify this result, in another case, the timber frame wall was modeled as the wall material, and the same option was selected in the IES interface, which is a timber frame wall. The difference in the results indicates that the selection in the Revit-IES interface overrides any selection made during modeling of the building in Revit. This is important because this indicates a gap in the information transfer in the building model in Revit and analytical model in IES-VE.

Figure 6 shows sample results of the daylighting analysis that users can get out of both the Ecotect and IES-VE tools and Figure 7 shows sample of the thermal analysis results generated by these tools. In Figure 6, daylighting simulation 


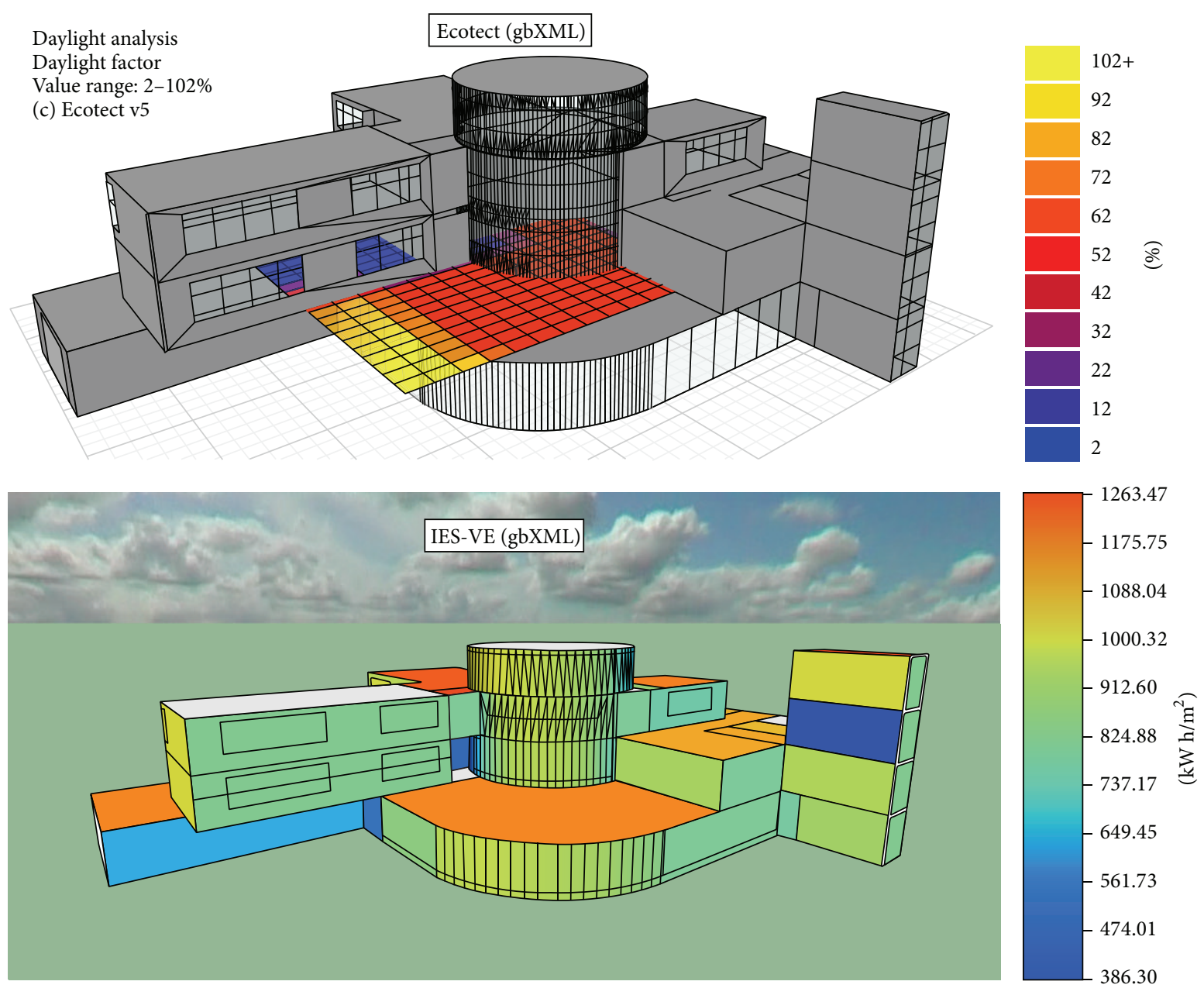

0.1/Jan-00:00 to 31/Dec-23:00

FIGURE 6: Snapshot of the sample daylighting simulation in Ecotect and IES-VE.

provides a visualization measurement of the daylight that is gained by every single surface inside the building's model as well as the building's exterior wall surfaces, which is supplied as a percentage of the solar light each surface can get. For example, at the second floor, the maximum percentage of solar gains is for central areas surrounded by glazed curtain walls with $72 \%$ while the minimum percentage is $12 \%$, which corresponds to corner areas located far from openings. IESVE provides solar analysis with 3D visualization showing the amount of light that varies between $386.3 \mathrm{kwh} / \mathrm{m}^{2}$ and $1263.47 \mathrm{kwh} / \mathrm{m}^{2}$ for the whole building.

In Figure 7, a diagram of total gains is based on outside temperature ranging from $-26^{\circ} \mathrm{C}$ to $32.5^{\circ} \mathrm{C}$ for the City of Montreal for all visible thermal zones. The maximum heat loss corresponding to $-26^{\circ} \mathrm{C}$ temperature is $-166 \mathrm{wh} / \mathrm{m}^{2}$ and the maximum gain is $54 \mathrm{wh} / \mathrm{m}^{2}$ corresponding to $32^{\circ} \mathrm{C}$. The part of the diagram with condensed points is for the temperature between $0^{\circ} \mathrm{C}$ to $26^{\circ} \mathrm{C}$, which gives an average of $-45 \mathrm{wh} / \mathrm{m}^{2}$ loss of energy and $10 \mathrm{wh} / \mathrm{m}^{2}$ energy gains, respectively. Gains breakdown results show the percentage of overall gains/losses for all visible thermal zones through different colors for Conduction, Solar-Air, Direct Solar, Ventilation,
Internal, and Inter-Zonal for a whole year from January 1 to December 31. As illustrated, conduction has a maximum overall loss with $69.4 \%$ (around $840 \mathrm{wh} / \mathrm{m}^{2}$ ) and direct solar has tremendous gains with $51.7 \%$ of energy gains (around $420 \mathrm{wh} / \mathrm{m}^{2}$ ). IES-VE also gives a total annual energy analysis, total electricity, and total net gas manifesting the total system energy based on power $(\mathrm{Kw})$ for the whole year. The analysis shows that the maximum energy consumption of the building is between January and December with an average of 250 (KW) for the whole system.

5.3. Assessing the LCA and Embodied Energy Analysis Results of Building Components (Step 3). Once the conceptual design is finished and the energy is analyzed, the building is assessed and analyzed based on the sustainability requirements using the LCA module and its associated tool (ATHENA Impact Estimator()). This user-friendly tool provides quick results in the form of tables and graphs. The Impact Estimator (IE) allows users to change the design, substitute materials, and make side-by-side comparisons. It also lets users compare similar projects with different floor areas on a unit floor area basis. After that, the IE is able to calculate the primary 

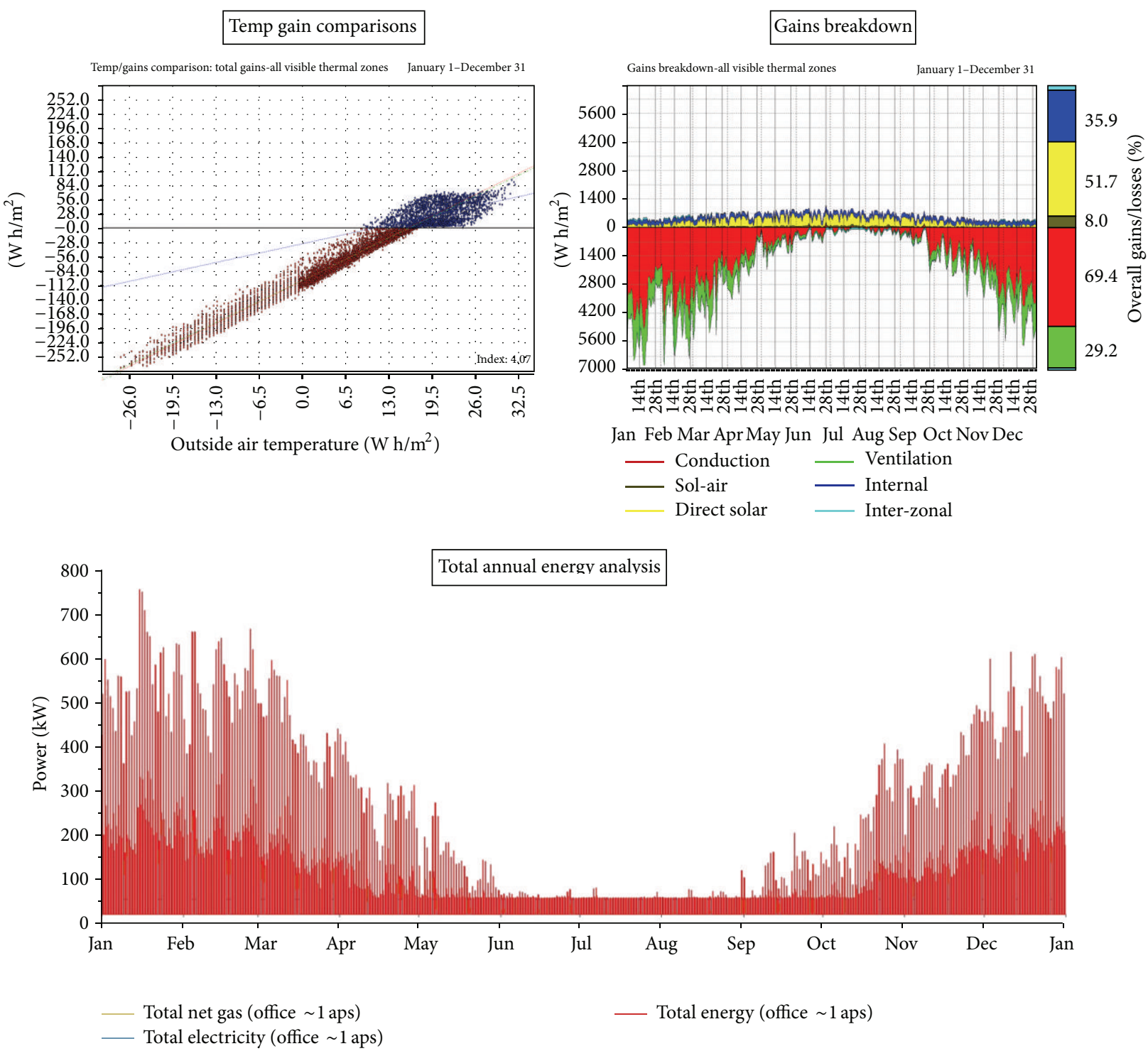

FIGURE 7: Snapshot of the sample thermal energy analysis in Ecotect.

operating energy including the embodied energy (the energy used to extract, refine, and deliver energy) and the related emissions to air, water, and land over the life cycle of the building [43]. Subsequently, the IE compares the life cycle of the operating and embodied energy and other environmental effects of the proposed building design by allowing users to better understand the inherent trade-offs associated with the increase of the envelope materials (e.g., insulation), which can reduce the operating energy consumption.

First, users input the necessary information such as geographic location, building life, occupancy/type, and, if desired, annual operating energy values into ATHENA. Second, the exported bill of quantities extracted in Step 1 is imported as text exchange file into ATHENA Impact Estimator $\odot$. Preset dialogue boxes prompt users to describe the different assemblies, such as entering the width, span, and live load of a floor assembly.
While the Impact Estimator offers a wide array of material and assembly combinations, the user needs to enhance the project design with additional materials. It should be noted that when it is decided to add "Extra Basic Materials," the application does not know how or where these materials are to be added and used. Hence, the LCA profile provided for extra basic materials is diminished in the sense that the application delivers the material to the building site but does not calculate any effects associated with the usage of this material. For instance, using the formerly mentioned case as an example, softwood lumber, which is a green material and is used in different parts of the building, is added beside other assembly groups as extra basic materials.

After entering all the necessary information, Impact Estimator provides series of reports in terms of (1) Primary Energy Consumption, (2) Acidification Potential, (3) Global Warming Potential, (4) Human Health (HH) Respiratory 
Fossil fuel consumption summary measure chart by assembly groups

Project Office building Montreal

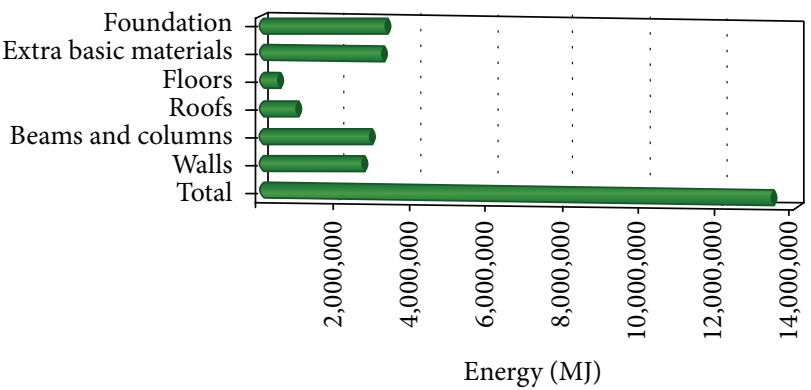

Smog potential summary measure chart by assembly groups

Project Office building Montreal

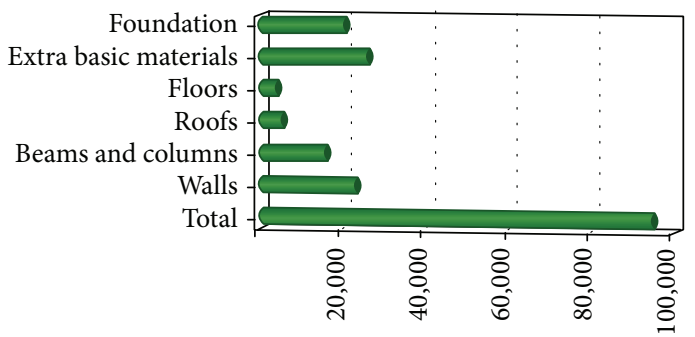

Smog potential ( $\left.\mathrm{kg} \mathrm{O}_{3} \mathrm{eq}\right)$

Acidification potential summary measure chart by assembly groups

Project Office building Montreal

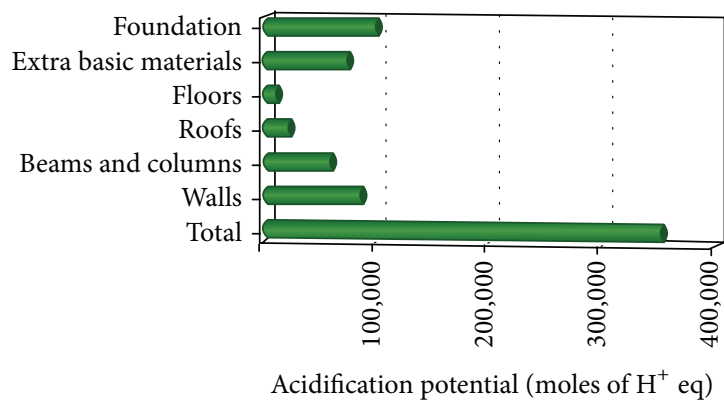

Ozone depletion potential summary measure chart by assembly groups

Project Office building Montreal

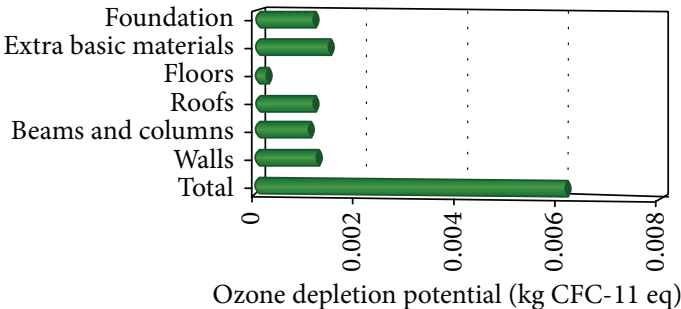

Global warming potential summary measure chart by assembly groups

Project Office building Montreal

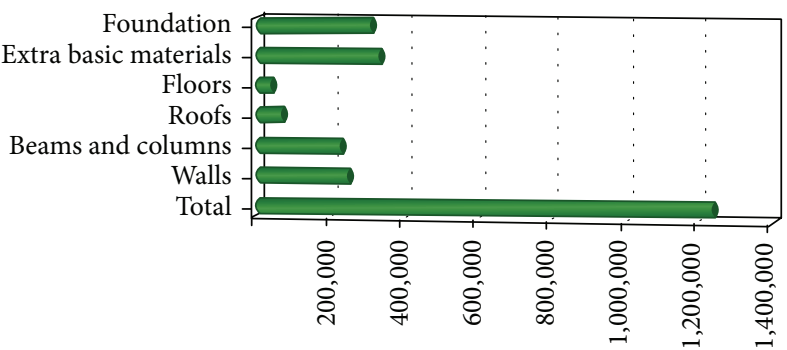

Global warming potential ( $\left.\mathrm{kg} \mathrm{CO} \mathrm{CO}_{2} \mathrm{eq}\right)$

$\mathrm{HH}$ criteria summary measure chart by assembly groups

Project Office building Montreal

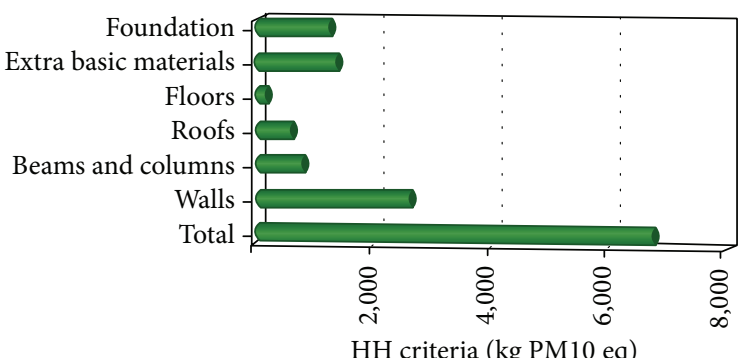

$\mathrm{HH}$ criteria (kg PM10 eq)

FIGURE 8: Environmental impact sample report of the implemented design.

Effects Potential, (5) Ozone Depletion Potential, (6) Photochemical Smog Potential, (7) Eutrophication Potential, and (8) Weighted Raw Resource Use, which are the focus of this case example. Figure 8 represents samples of the bar chart reports extracted from ATHENA Impact Estimator@. As shown in Figure 8, foundation as well as extra basic materials consumes fossil fuel more than other assembly groups (around 3,000,000 MJ). Beams and columns and walls use about 2,500,000 (MJ) of fossil fuel consumption. Conversely, when it comes to Ozone depletion, walls, roofs, and foundation with about 0.0014 (Kg CFC) are three groups with noticeable amounts. Rather than extra basic materials, walls, on the other hand, seem to have the most smog potential with around $22000\left(\mathrm{Kg} \mathrm{No}^{x}\right)$ out of the total amount, which is $95,000\left(\mathrm{Kg} \mathrm{No}^{x}\right)$. Foundation creates the highest amount of Global Warming Potential, averaging around 320,000 (Kg Co2), followed by the walls, with 240,000 (Kg Co2). Foundation and walls produce similar amount of acidification potential, usually around 85,000 (moles of $\mathrm{H}+$ ), whereas beams and columns produce much less than the others with around 55,000 (moles of H+). Similarly, the HH Respiratory Effects for walls have the most effects, averaging around 2280 out of a total of 6430 ( $\mathrm{Kg}$ PM2.5). In the ultimate interpretation among the selected components, walls and foundation have the most impact on the environment in comparison with other assembly groups. Two reasons for this can be described here. The former is that walls and foundation are in direct contact with the outdoor environment while having several openings (wants and voids) and the various layers of walls and foundation are not made from sustainable materials based on 

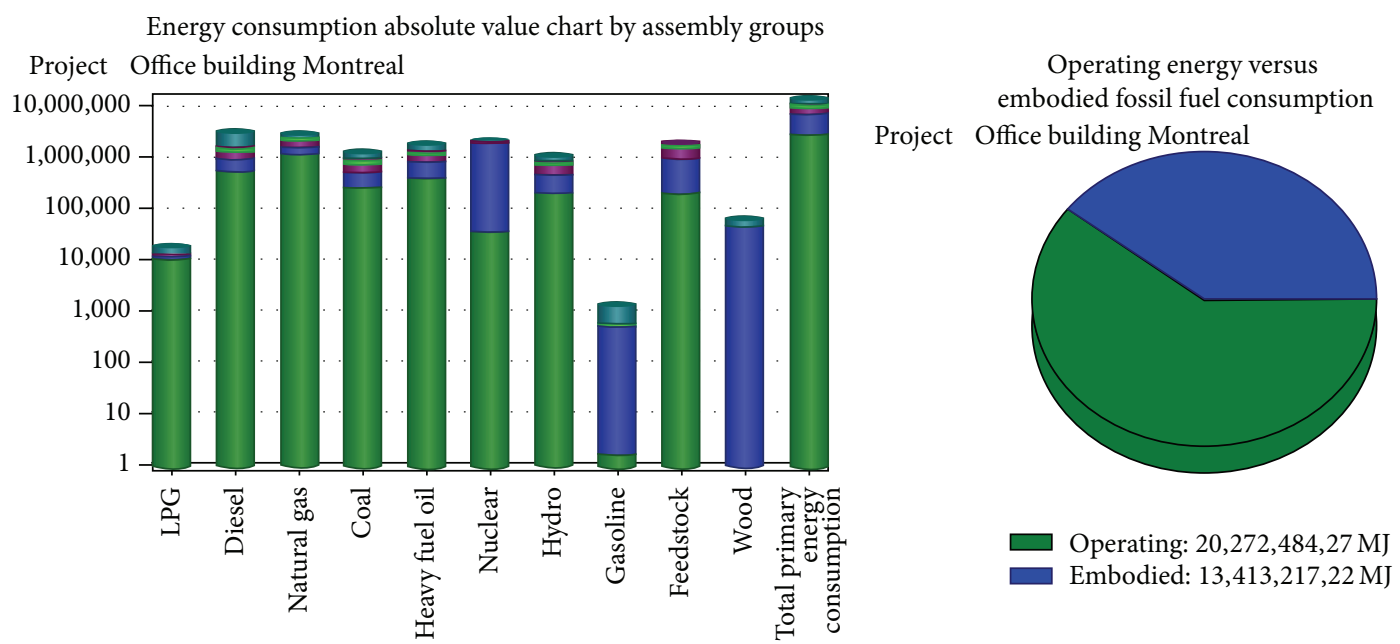

(MJ)

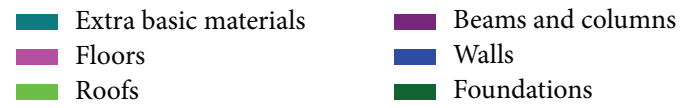

FIGURE 9: Embodied energy analysis of each building component in the designed model.

the information provided by the supplier. The latter reason is that all the green materials stored in the BIM model and its associated library are not supported by ATHENA Impact Estimator@. The results provided by ATHENA Impact Estimator` represent an appropriate overview about the EI of the design.

The embodied energy of every building's component is calculated and its result is generated and supplied as shown in Figure 9. IE takes into account the energy used to construct the structural elements of the building, the emissions to air, water, and land associated with the on-site construction activity, and the energy used to transport the materials and components from the manufacturer to a national distribution centre and from that centre to the building construction site. As illustrated in Figure 9, in the case building, it is obvious that the walls' materials have the highest embodied energy consumption with a total of $6,456,764 \mathrm{MJ}$ based on different types of energy description. Beams and columns have the second highest embodied energy consumption $(1,855,880 \mathrm{MJ})$. Furthermore, 20,272,484.27 MJ of the energy consumed in this building is operating fossil fuel energy while $13,413,217 \mathrm{MJ}$ is embodied fossil fuel energy.

To calculate the transportation embodied energy, a plugin is developed by authors based on the algorithm described in phase 5. The algorithm receives weight of every building component (lb) from user and implements the truck selection procedure. Then, the developed plug-in uses the API of Google map to calculate the distance between the location (origin) of the materials' suppliers and the location of the project (destination) once the required postal codes are entered by the user. As illustrated in Figure 10, when the required data (i.e., weight of the material, postal codes of origin, and destination) is entered, the plug-in calculates the transportation energy of every building component (MJ) as well as the number of trucks and their types. By clicking the "total" icon in the plug-in form, all the amounts of transportation energy in each section are added, which represents the total transportation energy. This amount has to be added to the embodied energy calculated by Athena. For example, by considering the materials of the walls' in the case building and by assuming a unit weight of $55 \mathrm{lb}$./SF and a calculated total surface area of 16,360 SF for all the walls, the total weight of the wall's material will be around $899,800 \mathrm{lb}$. Using the developed plug-in (Figure 10) shows that a combination of one truck of type 2 and thirteen trucks of type 4 is a proper option for transporting the materials. While the fuel consumption for truck 4 and truck 2 is $4.14 \mathrm{MPG}$ and 5.43 MPG, respectively, entering the postal code of the origin and destination would lead to an approximate measurement of the distance to be 9.1 miles; thus the consumed embodied energy for transporting the wall's material is calculated to be around 3988.8 MJ. Same processes are applied for the rest of the building components and accordingly the total transportation energy would be calculated to be around 38934.67 MJ, as shown in Figure 10.

\subsection{Environmental Evaluation and Calculation of the Potential} LEED Points (Step 4). By running the sustainability evaluator (EcoScorecard@) plug-in added on in BIM tool, designers are able to do a model evaluation based on different green building rating systems as described in the methodology and development section. The result of the EcoScorecard is shown in Figure 11, where $52.9 \%$ of the model's components are compiled from sustainable materials and families that are already defined in the Smart BIM database and detected by the EcoScorecard. By selecting the desired green building rating system and clicking the "evaluate model" button, users are able to see the analysis results in detail and save them as 


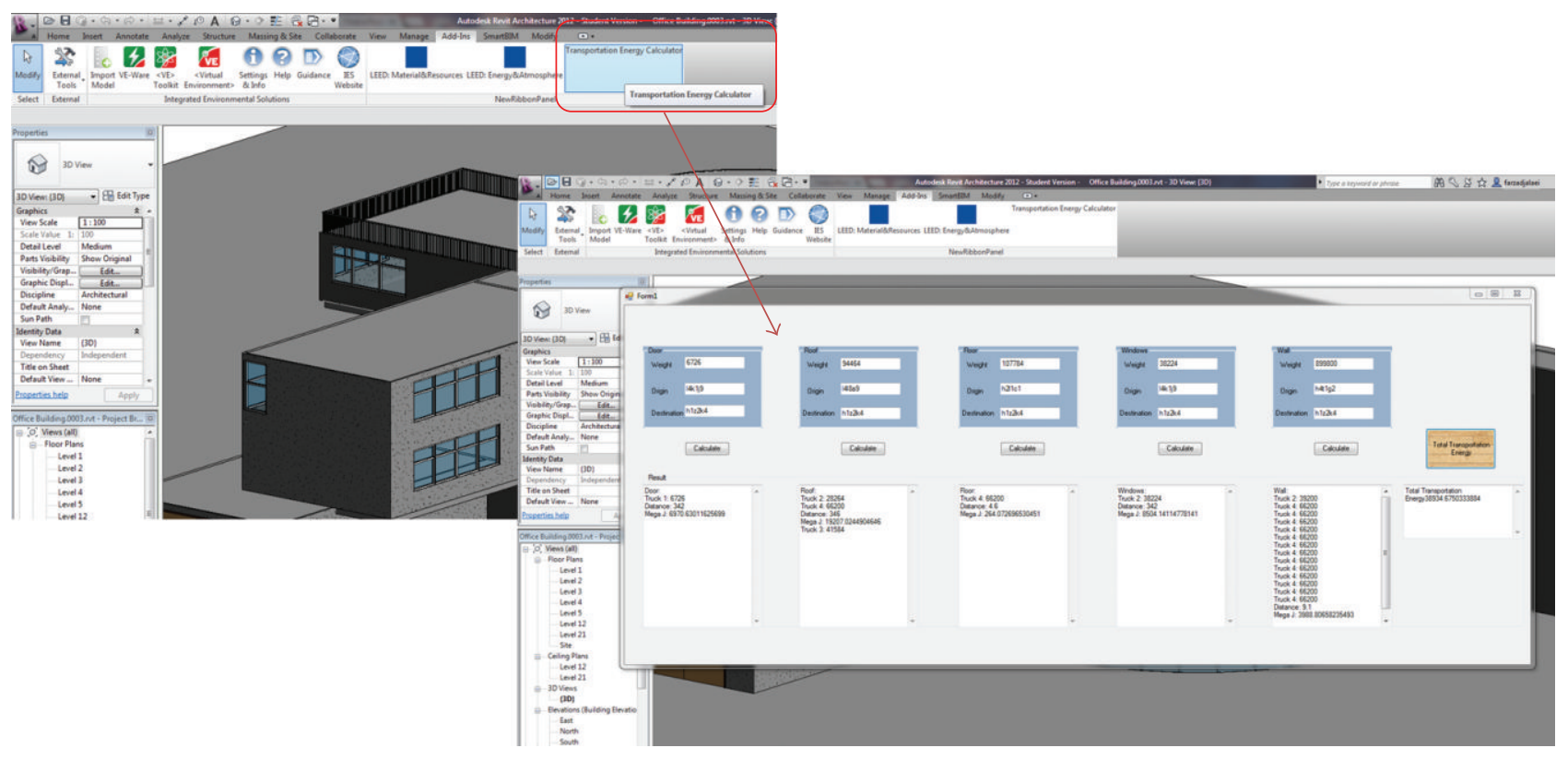

FIGURE 10: Snapshot of the developed plug-in to calculate the transportation embodied energy for every building component.

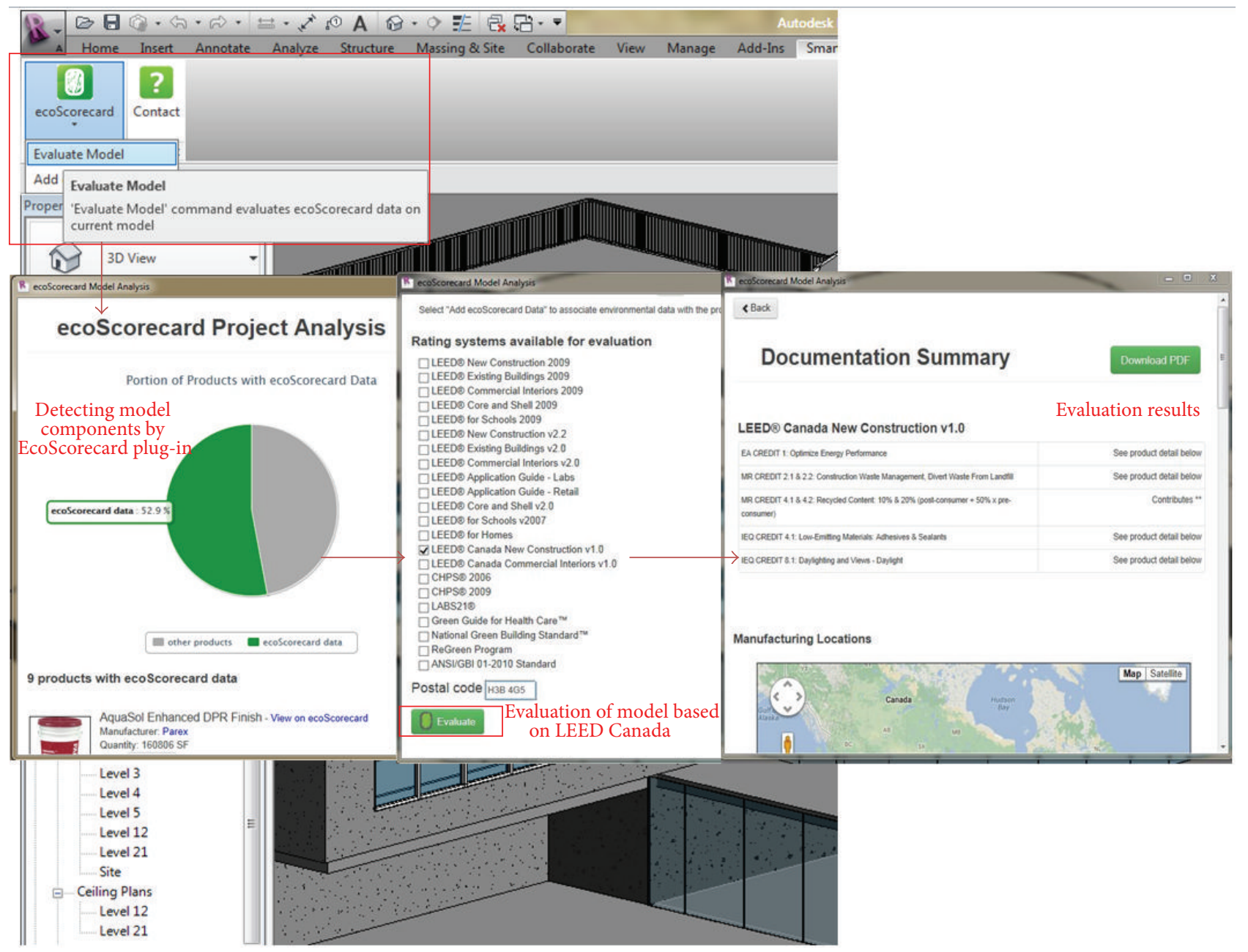

FIGURE 11: Snapshot of using EcoScorecard plug-in in Autodesk Revit to detect and evaluate model components based on LEED (CaGBC). 


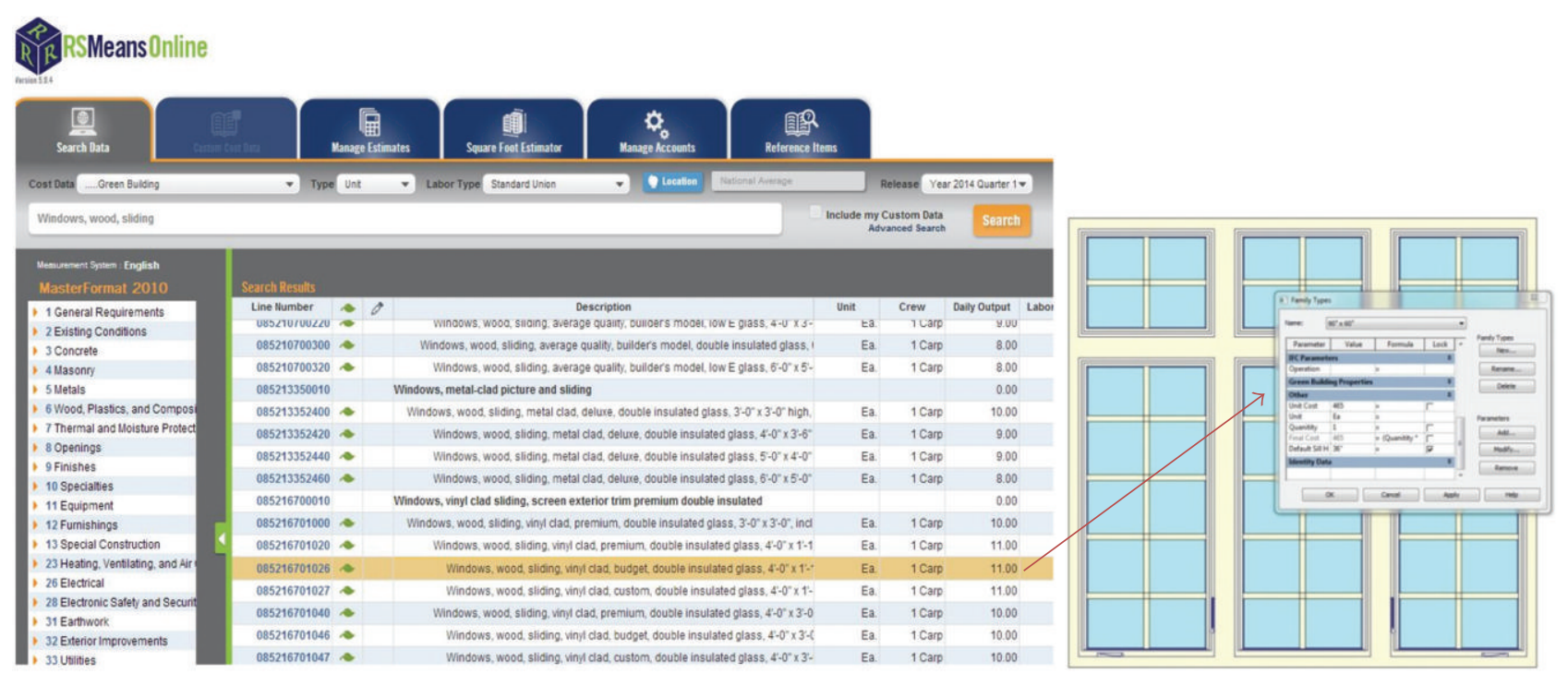

FIGURE 12: Snapshot of storing the unit cost of sustainable window family using RS-Means cost database.

a PDF file. In this paper, LEED Canada New Construction v1.0 is used to evaluate the designed model. In this case, the authors are able to identify the potential points earned by the $3 \mathrm{D}$ design based on the information provided by the EcoScorecard.

Table 3 offers information related to the materials and their associated potential LEED points as well as the actual points earned by the design developed in Step 1 based on the results of the EcoScorecard LEED evaluation. As shown in Table 3, the detected components by the plug-in that get 44 LEED points are based on the CaGBC rating system. This is an approximate number of the LEED points that are earned by the designed case building since the focus of this study is at the conceptual design stage, which means that the calculated points do not necessarily reflect the final number that can be earned when the building is completed. The intent is to simply provide owners and designers with an idea of how many potential LEED points the proposed building might earn if a decision is made to continue the project. At the conceptual stage, owners and designers do not have detailed information about the project, yet this integration will help them generate an approximated idea that will allow them to realize the potential LEED points the designed 3D model can earn.

Since not all suppliers provide the cost of products on their website, authors used RS-Means cost data to prepare preliminary cost estimate for the case building and store it in that specific family in BIM tool as shown in Figure 12. Table 4 illustrates the total estimated cost of each building component which is calculated using RS-Means Green Building Cost database. In this database the unit cost of each family is calculated based on the year 2013 national average value and adjusted for the city of Montreal. To prepare the cost estimate, materials with specifications similar to the quantity take off extracted from the developed 3D design are selected from RS-Means database. However, as illustrated in Table 4, the preliminary cost estimate of the building components using the proposed method is calculated to be $\$ 1,131,303.43$ while the actual estimated cost was calculated to be $\$ 1,045,753$ for year 2013 that reflects a 7\% difference in the values, which is acceptable for the conceptual stage where little information about the project is known.

\section{Conclusion}

The novelty highlighted in this paper describes the model's different modules, which are integrated into each other based on an automated process by creating new plug-ins and improving the functionality of the existing ones so that users will be able to start the sustainable design of a proposed building project at the conceptual stage of its life cycle in a timely and cost effective. Using a BIM integrated platform moves the design decisions forward at the early stage especially when comparing different design alternatives, which is considered as an attribute of this research.

The developed model enables users compare and select different materials and components, which are stored in the external database, to be used in their design based on the energy and sustainability specifications and cost. This accelerates the process of modifying building components early at the conceptual design stage in case the selected ones do not meet owners or designers requirements. Missing information during the transformation process from BIM tool to the other ones (i.e., energy analysis and simulation) includes the information required as input by different software. Some information needs to be entered manually by the user after the transferring process, while the other type of information is automatically assumed by the software itself (i.e., information about the type of materials when transferring it from Revit to Ecotect or IES-VE). The developed database was designed based on the collected information that contained limited numbers of certified components, all of which are designed and provided by the manufacturing companies. This is 


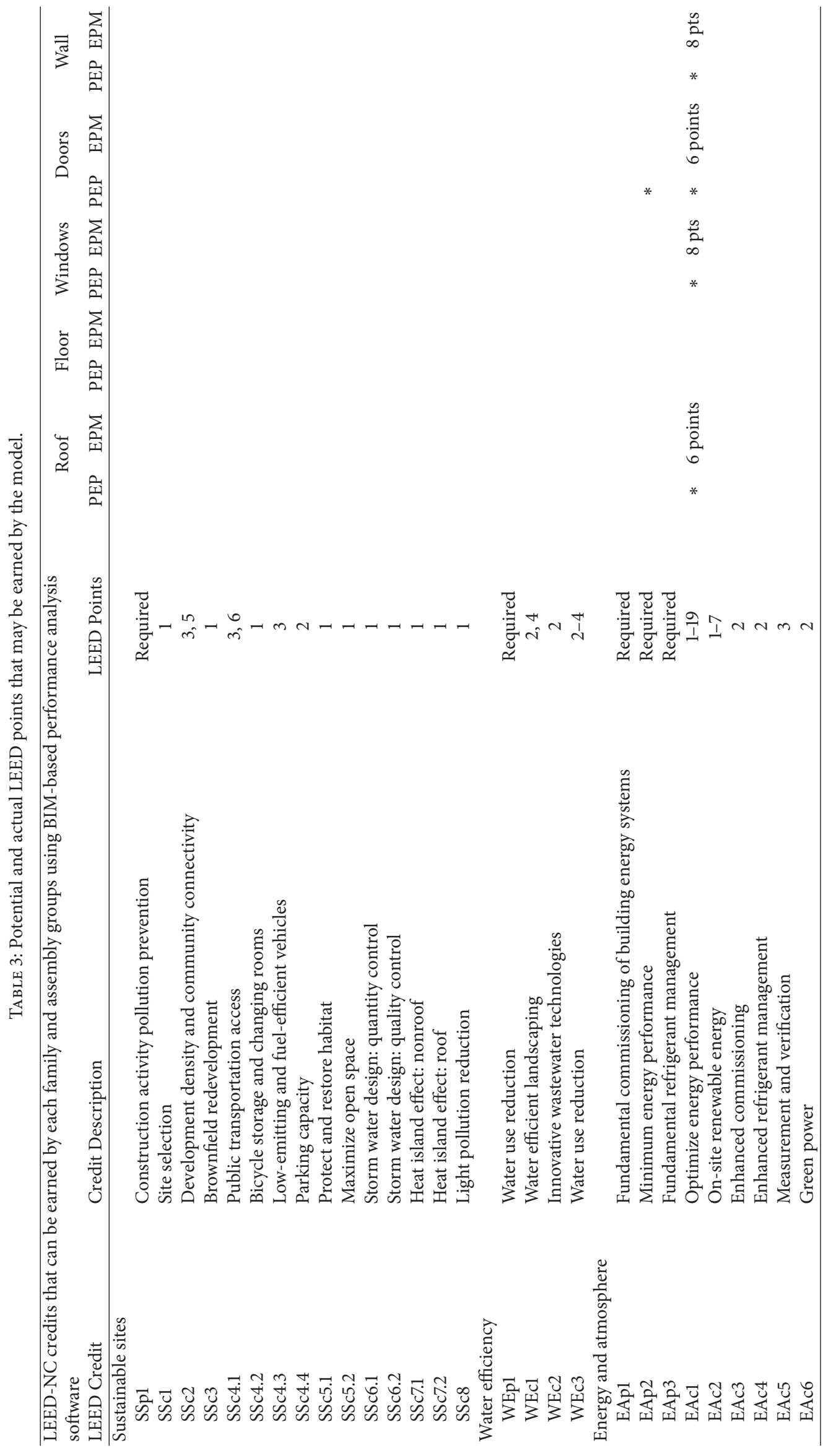




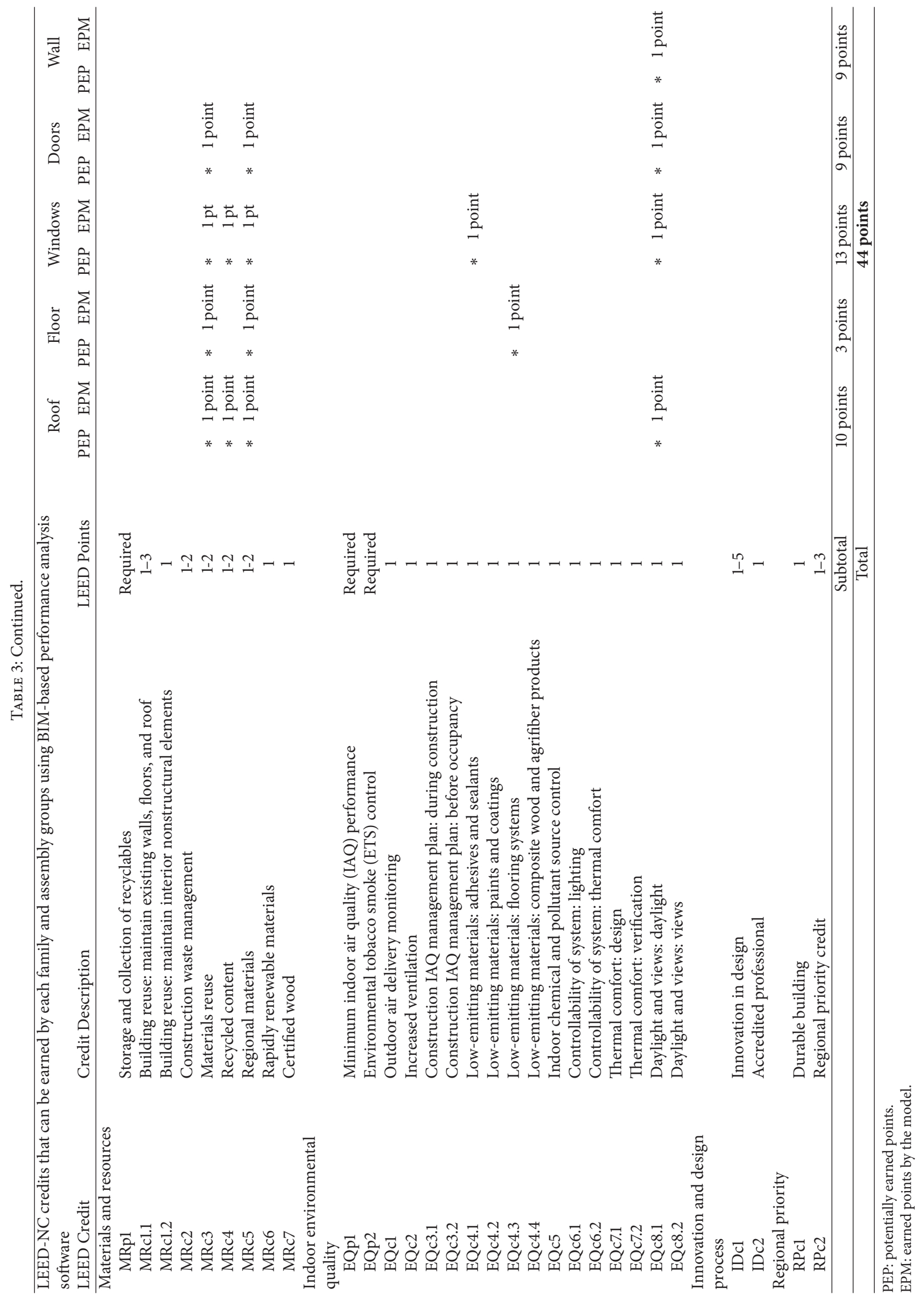




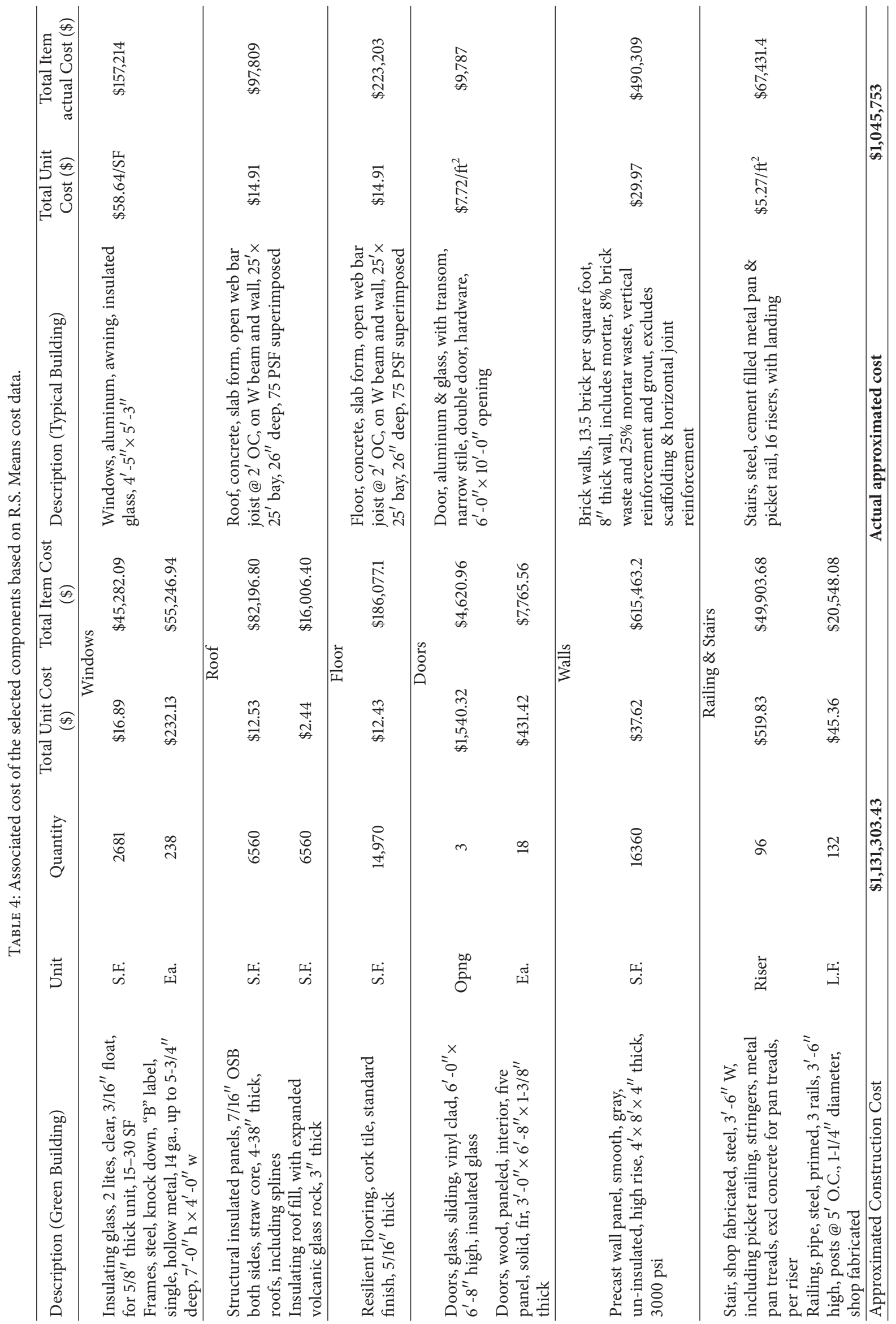


a limitation for the model because it does not cover all the existing green elements and, as was previously mentioned, only $52.9 \%$ of those materials and components were detected and defined in the EcoScorecard database. This means that there are several green families that need to be designed, converted to BIM format files, and added to the database.

In this research, different energy tools have been used and their results are compared. While Ecotect gives annual thermal consumption and peak loads for worst-case times, the IES Apache Simulator gives comprehensive information about the total annual energy consumption and room loads. The variation in Ecotect in terms of the heating and cooling loads is due to the calculation method used by this tool. Ecotect uses the worst design annual load case while the ASHRAE load calculator built into IES uses the worst monthly scenario (January) for heating loads and five months long (May-September) scenario for cooling loads. The discrepancy in the results between Revit, IES, and Ecotect was expected to occur because of the different load calculation techniques, calculation engines, and variation in the materials types and their associated values found in these tools.

The results generated by the different modules are evaluated based on diverse economical perspective. Energy analysis results are good feedback to the design team about the potential energy that can be gained or lost within a year by the proposed building. Using these data can ease the way of estimating the energy cost which is a major part of the operation cost for any building. LCA is in direct relation with life cycle cost through different attributes such as process-related costs, environmental insurance, impact on sales volume of the building components, labeling costs, and future taxes or abatement costs. Along with the obvious environmental advantages, LEED-certified buildings cost less to operate and are more desirable for commercial and residential occupants. As it is an ongoing research, part of the future work is related to enhance the external BIM database as well as developing a plug-in containing LEED points and requirements to efficiently calculate and quantify sustainability of the building components.

\section{Conflict of Interests}

The authors declare that there is no conflict of interests regarding the publication of this paper.

\section{References}

[1] A. Schlueter and F. Thesseling, "Building information model based energy/exergy performance assessment in early design stages," Automation in Construction, vol. 18, no. 2, pp. 153-163, 2009.

[2] K.-S. Jeong, K.-W. Lee, and H.-K. Lim, "Risk assessment on hazards for decommissioning safety of a nuclear facility," Annals of Nuclear Energy, vol. 37, no. 12, pp. 1751-1762, 2010.

[3] P. Crowther, "Design for disassembly to recover embodied energy," in Proceedings of the 16th Annual Conference on Passive and Low Energy Architecture, Cairns, Australia, 1999.
[4] E. Krygiel and B. Nies, Green BIM: Successful Sustainable Design with Building Information Modeling, John Wiley \& Sons, Indianapolis, Indiana, USA, 1st edition, 2008.

[5] J. L. Hoff, "Life cycle assessment and the LEED green building rating systems," in Proceedings of the RCI 23rd International Convention, Phoenix, Ariz, USA, 2008.

[6] M. M. Khasreen, P. F. G. Banfill, and G. F. Menzies, "Lifecycle assessment and the environmental impact of buildings: a review," Sustainability, vol. 1, no. 3, pp. 674-701, 2009.

[7] US Green Building Council (USGBC), Introduction to LEED, 2011, http://www.usgbc.org/DisplayPage.aspx?CMSPageID 1988.

[8] S. Kubba, Handbook of Green Building Design and Construction: LEED, BREEAM, and Green Globes, Butterworth-Heinemann, Oxford, UK, 2012.

[9] S. Azhar, W. A. Carlton, D. Olsen, and I. Ahmad, "Building information modeling for sustainable design and LEED rating analysis," Automation in Construction, vol. 20, no. 2, pp. 217-224, 2011.

[10] B. Becerik-Gerber and S. Rice, "The perceived value of building information modeling in the U.S. building industry," Journal of Information Technology in Construction, vol. 15, pp. 185-201, 2010.

[11] C. Kam and M. Fischer, "Capitalizing on early project decisionmaking opportunities to improve facility design, construction, and life-cycle performance-POP, PM4D, and decision dashboard approaches," Automation in Construction, vol. 13, no. 1, pp. 53-65, 2004.

[12] C. F. Hungu, Utilization of BIM from early design stage to facilitate efficient FM operations [M.S. thesis], Chalmers University of Technology, Göteborg, Sweden, 2013, http://publications.lib.chalmers.se/records/fulltext/183268/183268.pdf.

[13] S. Azhar, J. W. Brown, and A. Sattineni, "A case study of building performance analyses using building information modeling," in Proceedings of the 27th International Symposium on Automation and Robotics in Construction (ISARC '10), pp. 213-222, Bratislava, Slovakia, June 2010.

[14] S. Azhar and J. Brown, "BIM for sustainability analyses," International Journal of Construction Education and Research, vol. 5, no. 4, pp. 276-292, 2009.

[15] D. B. Crawley, J. W. Hand, M. Kummert, and B. T. Griffith, "Contrasting the capabilities of building energy performance simulation programs," Building and Environment, vol. 43, no. 4, pp. 661-673, 2008.

[16] F. Grobler, A Practical Guide to IFC or Surviving in the BIM Economy: What You Need to Know, AEC-ST, Orlando, Fla, USA, 2005.

[17] H. Abaza, "An interactive design advisor for energy efficient buildings," Journal of Green Building, vol. 3, no. 1, pp. 112-125, 2008.

[18] P. Dahl, M. Horman, T. Pohlman, and M. Pulaski, "Evaluating design-build operate- maintenance delivery as a tool for sustainability," in Proceedings of the Construction Research Congress, 2005.

[19] K. P. Lam, N. H. Wong, A. Mahdavi, K. K. Chan, Z. Kang, and S. Gupta, "SEMPER-II: an internet-based multi-domain building performance simulation environment for early design support," Automation in Construction, vol. 13, no. 5, pp. 651-663, 2004. 
[20] F. Jalaei and A. Jrade, "Integrating building information modeling (BIM), energy analysis and simulation tools to conceptually design sustainable buildings," in Proceedings of the 11th CSCE Conference, Montreal, Canada, May 2013.

[21] S. Kumar, Interoperability between building information modeling (BIM) and energy analysis programs [M.S. thesis], University of Southern California, Los Angeles, Calif, USA, 2008.

[22] J. B. Guinée, R. Heijungs, G. Huppes et al., "Life cycle assessment: past, present, and future," Environmental Science and Technology, vol. 45, no. 1, pp. 90-96, 2011.

[23] R. Ries and A. Mahdavi, "Integrated computational life-cycle assessment of buildings," Journal of Computing in Civil Engineering, vol. 15, no. 1, pp. 59-66, 2001.

[24] A. Jrade and F. Jalaei, "Integrating building information modelling with sustainability to design building projects at the conceptual stage," Journal of Building Simulation, vol. 6, no. 4, pp. 429-444, 2013.

[25] T. Häkkinen and A. Kiviniemi, "Sustainable building and BIM," in Proceedings of World Sustainable Building Conference (SB '08), Melbourne, Australia, 2008.

[26] J. Nässén, J. Holmberg, A. Wadeskog, and M. Nyman, “Direct and indirect energy use and carbon emissions in the production phase of buildings: an input-output analysis," Energy, vol. 32, no. 9, pp. 1593-1602, 2007.

[27] Y. L. Langston and C. A. Langston, "Reliability of building embodied energy modelling: an analysis of 30 Melbourne case studies," Construction Management and Economics, vol. 26, no. 2, pp. 147-160, 2008.

[28] G. Treloar, R. Fay, B. Ilozor, and P. Love, "Building materials selection: green strategies for built facilities," Facilities, vol. 19, no. 3-4, pp. 139-149, 2001.

[29] N. Wang, K. M. Fowler, and R. S. Sullivan, "Green building certification system review," Tech. Rep. PNNL-20966, U.S. Department of Energy, 2012.

[30] R. Baldwin, A. Yates, N. Howard, and S. Rao, BREEAM. Building Research Establishment Environmental Assessment Method for Offices, Watford, UK, 1998.

[31] GBCA (Green Building Council of Australia), 2008, GBCA website, http://www.gbca.org.au/.

[32] CASBEE (Comprehensive Assessment System for Building Environmental Efficiency), 2008, http://www.ibec.or.jp/CASBEE/english/index.htm.

[33] R. J. Cole, D. Rousseau, and G. T. Theaker, Building Environmental Performance Assessment Criteria, BEPAC Foundation, Vancouver, Canada, 1993.

[34] WBDG (Whole Building Design Guide), "Evaluating and Selecting Green Products," 2012, http://www.wbdg.org/resources/greenproducts.php.

[35] WGBC (World Green Building Council), 2008, http://www .worldgbc.org.

[36] R. M. Pulselli, E. Simoncini, F. M. Pulselli, and S. Bastianoni, "Emergy analysis of building manufacturing, maintenance and use: Em-building indices to evaluate housing sustainability," Energy and Buildings, vol. 39, no. 5, pp. 620-628, 2007.

[37] D. Bouchlaghem, H. Shang, J. Whyte, and A. Ganah, "Visualisation in architecture, engineering and construction (AEC)," Automation in Construction, vol. 14, no. 3, pp. 287-295, 2005.
[38] C. Eastman, P. Teicholz, R. Sacks, and K. Liston, BIM Handbook: A Guide to Building Information Modeling for Owner, Managers, Designers, Engineers, and Contractors, John Wiley \& Sons, New York, NY, USA, 1st edition, 2008.

[39] N. Young, S. Jones, H. Bernstein, and J. Gudgel, “The business value of BIM: getting building information modeling to the bottom line," McGrawHill Smart Market Report, 2009, http://www.trane.com/architect/Files/PDF/SMR\%20BIM\% 2009\%20FINAL\%20rev.pdf.

[40] S. S. Pimplikar and P. Esmaeili, "Building information modeling (BIM) and sustainability-using design technology in energy efficient modeling," IOSR Journal of Mechanical and Civil Engineering, pp. 10-21, 2012.

[41] P. Loucopoulos and R. Zicari, Conceptual Modeling, Databases, and CASE an Integrated View of Information Systems Development, John Wiley \& Sons, 1992.

[42] J. Irizarry, E. P. Karan, and F. Jalaei, "Integrating BIM and GIS to improve the visual monitoring of construction supply chain management," Automation in Construction, vol. 31, pp. 241-254, 2013.

[43] Athena Impact Estimator for Buildings V4.2 Software and Database Overview, 2012, http://calculatelca.com/wp-content/ uploads/2011/11/ImpactEstimatorSoftwareAndDatabaseOverview.pdf. 

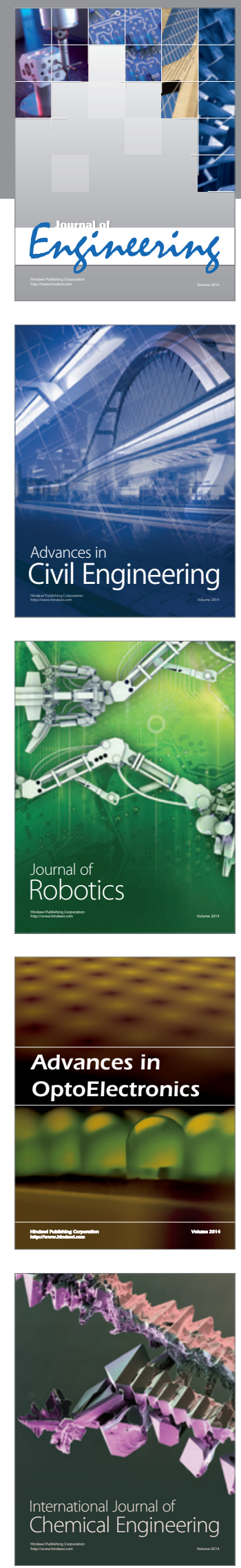

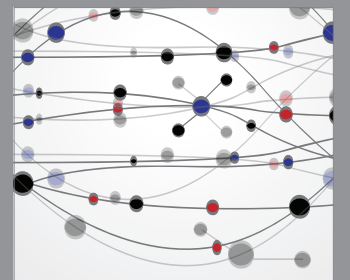

The Scientific World Journal
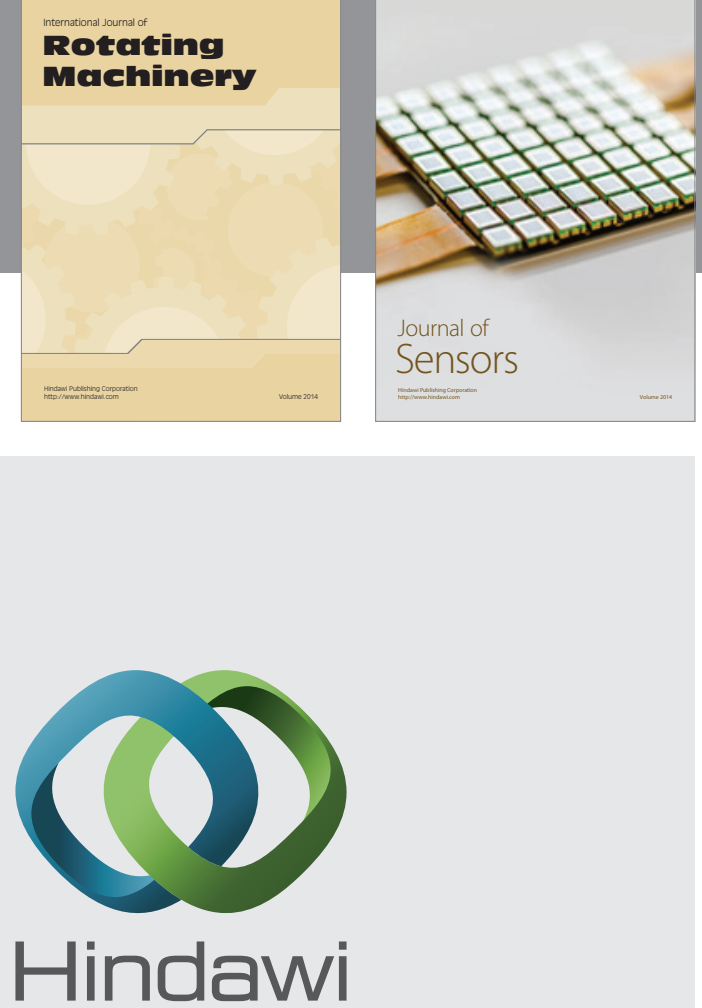

Submit your manuscripts at http://www.hindawi.com
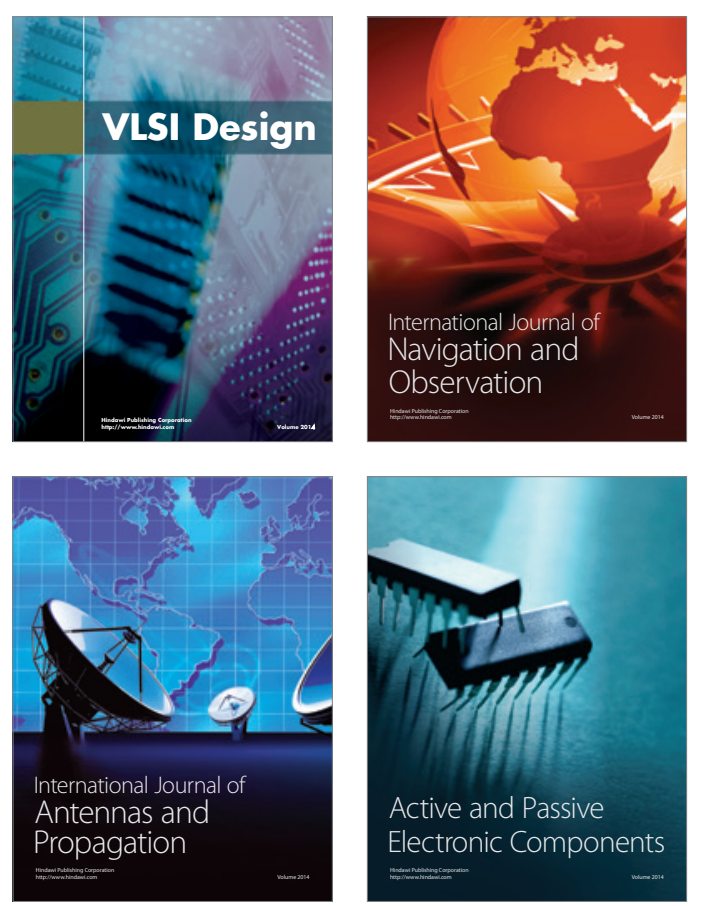
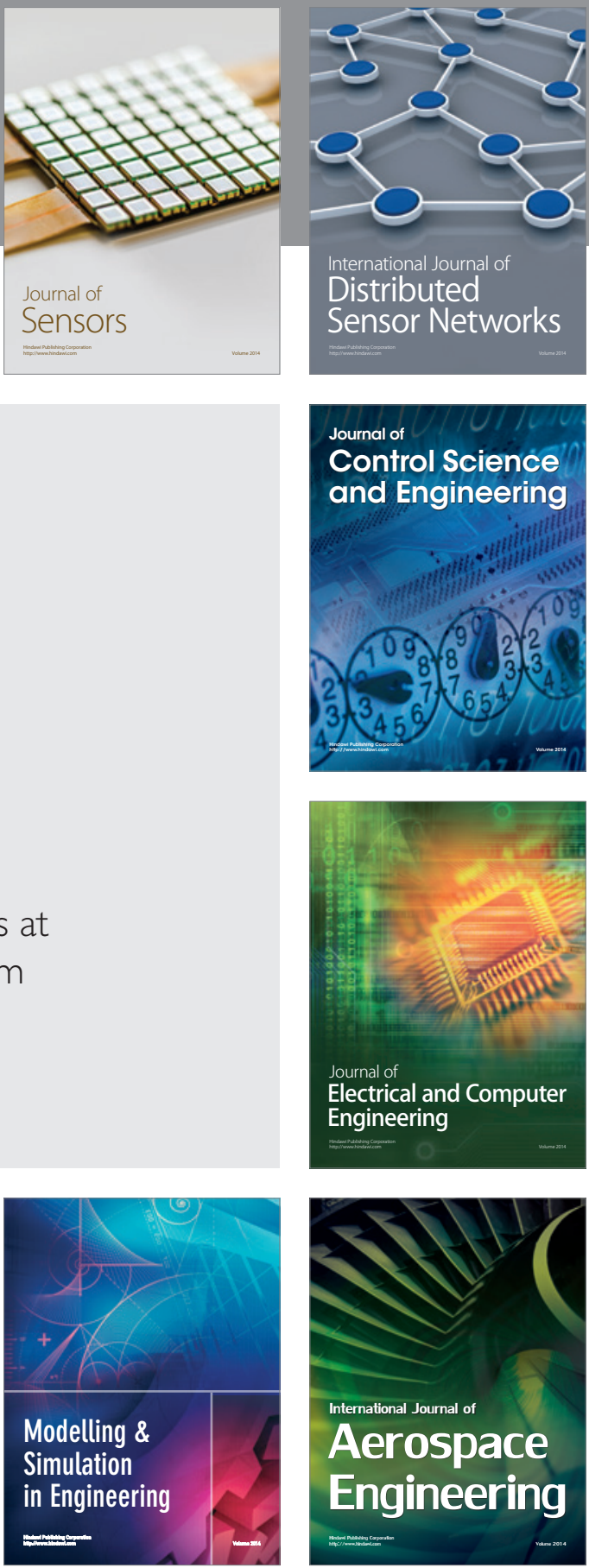

Journal of

Control Science

and Engineering
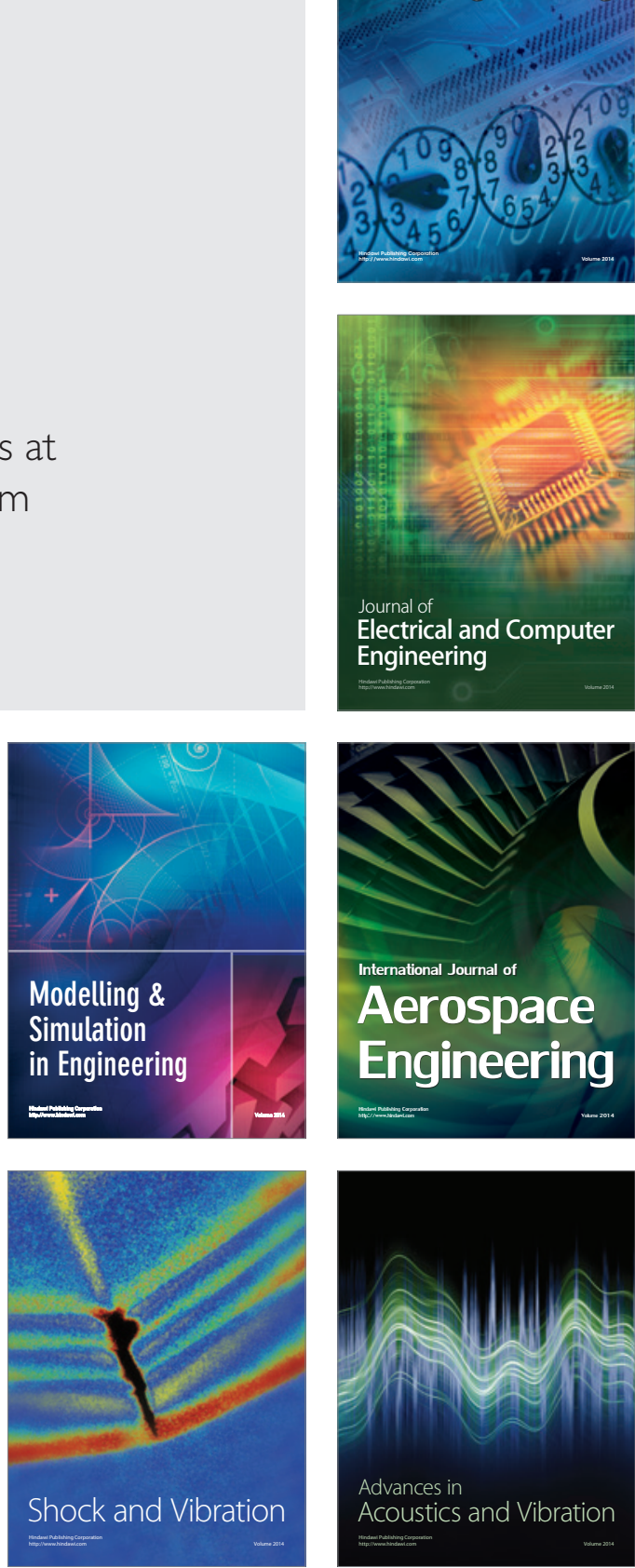